\title{
Ultrastructural and Flow Cytometric Analyses of Lipid Accumulation in Microalgae
}

\section{A Subcontract Report}

\author{
J. A. Solomon \\ R. E. Hand, Jr. \\ R. C. Mann \\ Oak Ridge National Laboratory \\ Oak Ridge, TN
}

December 1986

SERI Technical Monitor:

D. A. Johnson

Prepared under Subcontract No. DK-4-4142-1

Solar Energy Research Institute

A Division of Midwest Research Institute

1617 Cole Boulevard

Golden, Colorado 80401-3393

Prepared for the

U.S. Department of Energy

Contract No. DE-AC02-83CH10093 


\section{NOTICE}

This report was prepared as an account of work sponsored by the United States Government. Neither the United States nor the United States Department of Energy, nor any of their employees, nor any of their contractors, subcontractors, or their employees, makes any warranty, expressed or implied, or assumes any legal liability or responsibility for the accuracy, completeness or usefulness of any information, apparatus. product or process disclosed, or represents that its use would not infringe privately owned rights.

\section{Printed in the United States of America \\ Available from: \\ National Technical Information Service \\ U.S. Department of Commerce \\ 5285 Port Royal Road \\ Springfield, VA 22161}

Price: Microfiche $\mathrm{AO1}$

Codes are used for pricing all publications. The code is determined by the number of pages in the publication. Information pertaining to the pricing codes can be found in the current issue of the following publications. which are generally available in most libraries: Energy Research Abstracts. (ERA): Government Reports Announcements and Index (GRA and I); Scientific and Technical Abstract Reports (STAR); and publication, NTIS-PR-360 available from NTIS at the above address. 


\section{PREFACE}

This report is a summary of research on the use of flow cytometry to sort microalgae cells and ultrastructural changes in algae cells during lipid accumulation. It was submitted in partial fulfillment of Purchase Order No. DK-4-04142-1. The work was performed under subcontract to SERI with funds provided by the Biofuels and Energy from Municipal Waste Division of the U.S. Department of Energy.

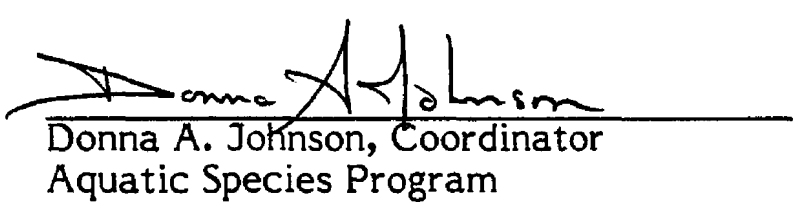

Approved for

SOLAR ENERGY RESEARCH INSTITUTE

Stanley R. Bull, Dirlector

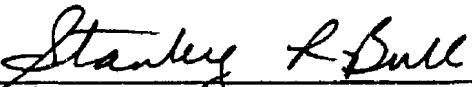

Solar Fuels Research Division 
ABSTRACT

Lipid accumulation in three species of microalgae was investigated with flow cytometry (FCM) and transinission electron microscopy (TEM). Previous studies using batch cultures of algae have led to the assumption that lipid accumulation in microalgae is a gradual process requiring at least several days for completion. However, FCM reveals, through changes in the chlorophyll:lipid ratio, that the time span required for individual cells to change metabolic state is short. Simultaneous FCM measurements of chlorophyll and nile red (neutral lipid) fluorescence in individual cells of nitrogen-deficient Isochrysis populations revealed a bimodal population distribution as one stage in the lipid accumulation process. The fact that two discrete populations exist, with few cells in an intermediate stage, suggests rapid response to a lipid trigger. Interpretations of light and electron microscopic observations are consistent with this hypothesis. The time required for an entire population to achieve maximum lipid content is considerably longer than that required for a single cell, due to the variation in response time among cells. In this study high lipid cultures were sometimes obtained by using $\mathrm{FCM}$ to separate high lipid cells from the remainder of the population. FCM holds much promise for strain enhancement but considerable developmental work, directed at providing more consistent results, remains to be done. 
INTRODUCTION

As a result of the oil embargo of the early 1970s, considerable attention was focused on renewable sources of energy. Microalgae offer promise in this regard for several reasons. Many species are able to directly convert sunlight and carbon dioxide into oils which can replace oil imports without expensive conversion steps (SERI 1985). In addition, microalgae can be grown using low-value resources (such as saline waters in arid lands), and their biomass yields compare favorably with those of terrestrial plants (Dubinsky et al. 1979).

Much of the initial research effort of the Aquatic Species Program (ASP), Solar Energy Research Institute (SERI) has centered on the isolation and identification of microalgal species. These strains are capable of accumulating large quantities of lipids and can flourish under the harsh environmental conditions imposed by the North American southwestern desert. As a collection of potential lipid-accumulating species becomes available, research attention is shifting (1) to understand the physiological mechanisms involved in lipid production, (2) to identify reliable ways to induce lipid accumulation (lipid "triggers"), and (3) to enhance lipid production by high lipid producing algal strains.

The goals of this study were twofold. Task 1 involved the examination of subcellular changes occurring during lipid accumulation in three microalgal species, as an aid toward understanding the underlying physiological mechanisms. In Task 2, the feasibility of 
using flow cytometry (FCM) to enhance the lipid accumulating potential of species from the SERI microalgal culture collection (SERI 1986) was investigated.

\section{MATERIALS AND METHODS}

CULTURE

Three species were obtained from the SERI microalgal culture collection: Ankistrodesmus falcatus (S/ANKIS-1), Isochrysis aff. galbana (S/ISOCH-1), and Nannochloropsis salina (S/NANNO-1). Ankistrodesmus was cultured in Pyramid Lake medium and the two remaining species in $\mathrm{f} / 2$ medium (SERI 1986), which was sterilized by autoclaving. The initial $f / 2$ medium was made using filtered sea water from Beaufort, North Carolina, but artificial sea water (Rila Products, Teaneck, N.J.) was later used as a base. All cultures were maintained at $27^{\circ} \mathrm{C}$ under a $16 \mathrm{~h}$ light:8 $\mathrm{h}$ dark cycle. The light intensity in the culture chamber was approximately $37 \mu \mathrm{E} \mathrm{m}^{-2} \mathrm{~s}^{-1}$ using a mixture of fluorescent and incandescent bulbs. Because Ankistrodesmus grew poorly at this high light intensity, neutral density filters were used to provide a reduced intensity of about $4 \mu \mathrm{E} \mathrm{m}^{-2} \mathrm{~s}^{-1}$. Isochrysis and Nannochloropsis were maintained on an orbital shaker; Ankistrodesmus was not shaken.

In one experiment, exponentially growing and nutrient stressed cultures of Boekelovia sp. (previously called Chryso F-1) were obtained from Dr. Bill Barclay at SERI. Both living cells and duplicate cultures fixed with $2 \%$ glutaraldehyde before shipment were analyzed with FCM. 
INDUCTION OF LIPID ACCUMULATION

Nitrogen deficiency was used to induce lipid accumulation in all three species. A heaithy, rapidly growing culture was centrifuged and the cell pellet resuspended in a nitrogen-deficient culture medium ( $f / 2$ or Pyramid Lake medium from which the nitrogen source had been omitted). In some cases, particularly with the motile Isochrysis, a good pellet did not form, so the procedure was repeated one or more times to remove as much nitrogen-containing medium as possible.

\section{ELECTRON MICROSCOPY}

Several different preparative procedures were used initially, in order to determine which would be most appropriate for each of the three algal species (see Table 1 ). Based on results from the preliminary fixations, procedure 5 was used for routine preparations of Ankistrodesmus and Nannochloropsis, with the addition of $0.25 \mathrm{M}$ sucrose to both the primary and secondary fixative mixtures, to approximate the osmolarity of the growth medium. For fixation of Isochrysis, procedure 3 was modified; Sorenson's phosphate buffer and $0.25 \mathrm{M}$ sucrose were used in the fixation mixture and the secondary fixation step was omitted. Isochrysis and Nannochlorops is were fixed on days $0,1,3,5,7$, and 13 and Ankistrodesmus on days $0,1,2,3,5,7$, and 10 of nitrogen deprivation.

Thin sections (70-100 nm thick) were cut on a Sorval MT-2 ultramicrotome, using a Dupont dianond knife. Sections were poststained with either aqueous or methanolic uranyl acetate and lead citrate and were examined using a Zeiss EM 9S-2 (60 kV operating voltage), a Hitachi $H-600(100 \mathrm{kV})$, or, in the majority of cases, a JEOL Jem 100CX (100 kV) transmission electron microscope. 
Table 1. Summary of Preparative Procedures Used

\begin{tabular}{|c|c|c|c|c|c|c|c|}
\hline $\begin{array}{l}\text { Procedure } \\
\text { number }\end{array}$ & $\begin{array}{l}\text { Primary } \\
\text { fixation }\end{array}$ & Duration & $\begin{array}{l}\text { Secondary } \\
\text { fixation }\end{array}$ & Duration & Temperature & Dehydration & Embedd ing \\
\hline 1 & $\begin{array}{l}\text { Glutaraldehyde } \\
\text { added directly } \\
\text { to culture } \\
\text { medium, } 1 \% \text { final } \\
\text { concentration }\end{array}$ & $1.3 \mathrm{~h}$ & $\begin{array}{l}1 \% \mathrm{OsO}_{4} \text { in } \\
\text { sea water }\end{array}$ & l $\mathrm{h}$ & Room & $\begin{array}{l}\text { Acetone series } \\
\text { on ice }\end{array}$ & $\begin{array}{l}\text { Spurr's low } \\
\text { viscosity } \\
\text { resin }\end{array}$ \\
\hline 2 & $\begin{array}{l}\text { 4\% glutaraldehyde } \\
\text { with } 1 \% 0 \mathrm{sO}_{4} \\
\text { in phosphate } \\
\text { buffer, pH } 6.8\end{array}$ & $10 \mathrm{~min}$ & none & & Room & $\begin{array}{l}\text { Acetone series } \\
\text { on ice }\end{array}$ & $\begin{array}{l}\text { Spurr's low } \\
\text { viscosity } \\
\text { resin }\end{array}$ \\
\hline 3 & $\begin{array}{l}\text { 2x glutaraldehyde } \\
\text { with } 2 \mathrm{OSO}_{4}\end{array}$ & $15 \min$ & $\begin{array}{l}0.5 \% \mathrm{OSO}_{4} \text { in } \\
\text { cacodylate } \\
\text { buffer, pH } 7.3\end{array}$ & $35 \min$ & Room & $\begin{array}{l}\text { Acetone series } \\
\text { on ice }\end{array}$ & $\begin{array}{l}\text { Spurr's low } \\
\text { viscosity } \\
\text { resin }\end{array}$ \\
\hline 4 & $\begin{array}{l}2 \% \text { glutara ldehyde } \\
\text { in phosphate } \\
\text { buffer. pH } 8.0\end{array}$ & $45 \mathrm{~min}$ & $\begin{array}{l}0.5 \% \mathrm{OsO}_{4} \text { in } \\
\text { phosphate } \\
\text { buffer, pH } 8.0\end{array}$ & $l \mathrm{~h}$ & $4^{\circ} \mathrm{C}$ & $\begin{array}{l}\text { Ethanol, } \\
\text { propylene } \\
\text { oxide on } \\
\text { ice }\end{array}$ & $\begin{array}{l}\text { Araldite/ } \\
\text { EMbed } 812\end{array}$ \\
\hline 3 & $\begin{array}{l}2 \% \text { glutara ldehyde } \\
\text { in } 0.1 \mathrm{M} \mathrm{cacodylate} \\
\text { buffer. pH } 1.3 \\
\text { with } 0.05 \% \mathrm{CaCl}_{2}\end{array}$ & $45 \mathrm{~min}$ & $\begin{array}{l}0.5 \% \mathrm{OsO}_{4} \text { in } \\
0.1 \mathrm{M} \text { cacodylate } \\
\text { buffer, } \mathrm{pH} 7.3\end{array}$ & I $h$ & $4^{\circ} \mathrm{C}$ & $\begin{array}{l}\text { Ethanol, } \\
\text { propylene } \\
\text { oxide on } \\
\text { ice }\end{array}$ & $\begin{array}{l}\text { Araldite/ } \\
\text { EMbed } 812\end{array}$ \\
\hline
\end{tabular}




\section{FLUORESCENT STAINING}

Nile red, originally purified from nile blue by Greenspan et al. (1985), was used as an intracellular neutral-lipid-specific stain, both for epifluorescent light microscopy and for FCM. Nile red powder (Molecular Probes, Junction City, Oregon) was added to either acetone or heptane at a dye concentration of $0.1 \mathrm{mg} / \mathrm{mL}$. Dissolution in heptane was incomplete at this concentration; the saturated solution was used as a stock for later dilutions for a final concentration of 1 to $2 \mu \mathrm{g} / \mathrm{mL}$ culture medium. Based on prelimary observations and theoretical considerations, the heptane preparation was used for routine analysis and sorting. The dye was added to a suspension of algal cells in the culture medium and the mixture was allowed to equilibrate for at least 5 min before microscopic examination or 30 min before FCM.

FLOW CYTOMETRIC ANALYSIS AND SORTING

An Ortho Diagnostics $50 \mathrm{H}$ research flow cytometer equipped with dual lasers was used for cell measurement and sorting (see Appendix). Cells were stained as described above, and the parent culture was monitored throughout sorting using epifluorescence microscopy. The population was continually stirred during sorting. A wavelength of $488 \mathrm{~nm}$ was used for excitation; an emission range of 520 to $580 \mathrm{~nm}$ was used to measure nile red fluorescence, and $>630 \mathrm{~nm}$ indicated chlorophyll autofluorescence. 
RESULTS

\section{ELECTRON MICROSCOPY}

\section{Ankistrodesmus falcatus}

Individual cells can be described as needle-like: they are 40 to $50 \mathrm{~mm}$ long by 2 to $3 \mathrm{\mu m}$ in diameter. Cells from exponentially growing populations are pictured in Figs. 1-4, while nitrogen-deficient cells are shown in Figs. 5-8. The cells are nearly circular in cross section, with one parietal chloroplast (C) extending most of the cell length (Fig. 1). Within the chloroplast, starch granules (S) accumulate between the chloroplast lamellae (Figs. 4, 5, 7, and 8); dense granules (G) similar in appearance to the granules of chlorophycean eyespots, are also occasionally seen within the chloroplast (Fig. 4). Mitochondrial lobes (M), possibly joined to form one large reticulate mitochondrion, are located adjacent to the proximal portion of the chloroplast (Figs. 1,3, 7, and 8 ). The remainder of the cell consists of cytoplasm, occasional vesiculate structures, one median nucleus $(N)$ and the cell wall (Fig. 1). A possible microbody is identified in Fig. 3 (arrow).

The most obvious difference between exponentially growing (nitrogen-sufficient) and nitrogen-deficient cells is the accumulation of large numbers of lipid droplets (L) in the latter (Figs. 5-8). The oil droplets form in the cytoplasm external to the chloroplast and often appear to be clustered about the mitochondrion (Figs. 7 and 8 ). The usual arrangement consists of chloroplast, adjacent mitochondrion, and lipid globules. Nitrogen-stressed cells commonly contain large 
quantities of both starch granules and lipid globules (Figs. 5, 7 , and 8 ). Another organelle often found in the region of the lipid droplets consists of densely packed, concentric layers of double membrane (OM, Figs. 2, 6, and 7). The double membrane structure resembles the chromoplast of some higher plant flower petals in which hydrocarbon-related carotenoids accumulate, producing the distinctive color of the petals (see e.g. Graham and Wareing, 1976, p. 287). A continuous layer of double membrane, suggestive of endoplasmic reticulum, often lines the distal borders of the lipid droplets (Fig. 6, arrow).

\section{Isochrysis aff. galbana}

Figure 9 gives an overview of the spatial organization of Isochrysis aff. galbana. The ultrastructure of nutrient-sufficient cells is shown in Figs. 10-14 and that of nutrient-deficient cells in Figs. 15-17. The ovoid cell contains two parietal chloroplasts, each with a pyrenoid (Fig. 13) penetrated by a double thylakoid membrane. The thylakoids of the chloroplasts are arranged in triple layers (Figs. 12 and 13), although distensions of these membranes are very common (Figs. 10 and 11). Within the cup formed by the two chloroplasts lies the large, centrally located nucleus (N). Mitochondria $(M)$ often occur in close association with the chloroplasts (Fig. 14). The nuclear membrane is continuous with the chloroplast endoplasmic reticulum (Fig. 11, arrowhead). The anterior portion of the cell contains the remaining organelles: a Golgi apparatus (GA), several mitochondria (or lobes of one continuous mitochondrion). vesicles, and the flagellar apparatus (Fig. 9). The entire cell body 
Fig. 1-4. Nitrogen-sufficient cells of Ankistrodesmus falcatus. Scale bars $=0.5 \mu \mathrm{m}$.

Fig. 1. A longitudinal median section of a portion of the cell shows one long parietal chloroplast $(C)$ and the nucleus (N), with a mitochondrion (M) between them.

Fig. 2. Concentric rings of the double membranous organelle (DM) lie near the chloroplast.

Fig. 3. A mitochondrion (M) and possibly a microbody (arrow) are located near the chloroplast. The starch granules (S) lie within the stroma, between the photosynthetic lamellae.

Fig. 4. In oblique view, numerous starch granules (S) can be seen packing the chloroplast. $G=$ dense granule. 

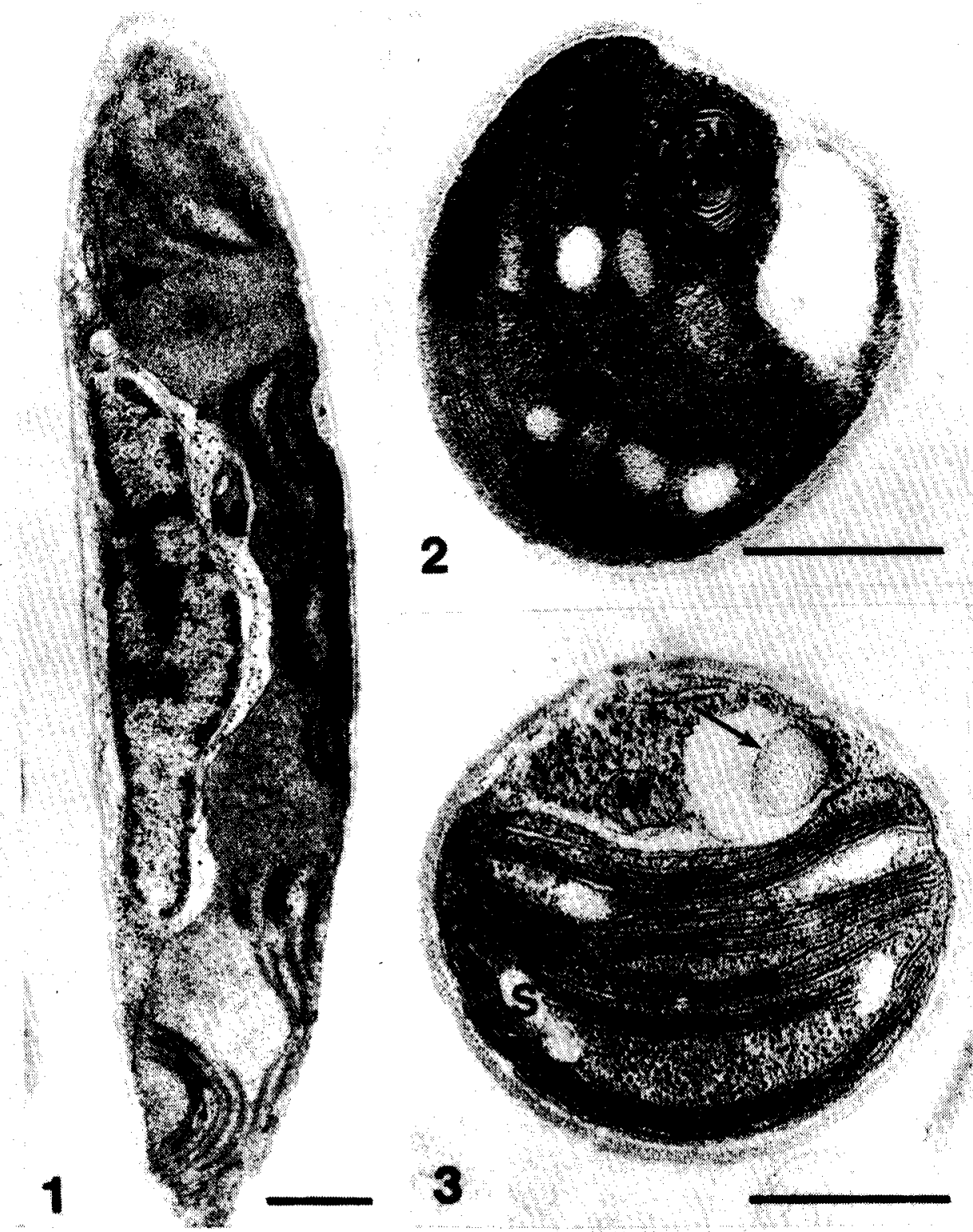






Figs. 5-8. Nitrogen-stressed cells of Ankistrodesmus falcatus. Scale bars $=0.5 \mu \mathrm{m}$.

Fig. 5. In this oblique section, food storage bodies occupy a large proportion of the cell volume. Starch granules (S) fill the chloroplast, and lipid droplets (L) occupy most of the cytoplasmic region. The nucleus $(N)$ and double membrane structure (OM) are also present.

Fig. 6. Tightly packed lipid droplets f 111 the cytoplasmic portion of the the cell. Two double membrane structures (DM) lie nearby, and a double layer of membrane (arrows) lines the volume occupied by the lipid droplets.

Fig. 7. This cross-sectional view shows the relationship between the chloroplast (C) with starch granules (S) and the cytoplasmic region, which contains lipid droplets $(L)$, mitochondrion (M), and a double membrane structure (DM).

Fig. 8. Cross section through four autospores retained within the mother cell wall. A mitochondrion (arrows) is often centrally located between chloroplast and lipid droplets. 


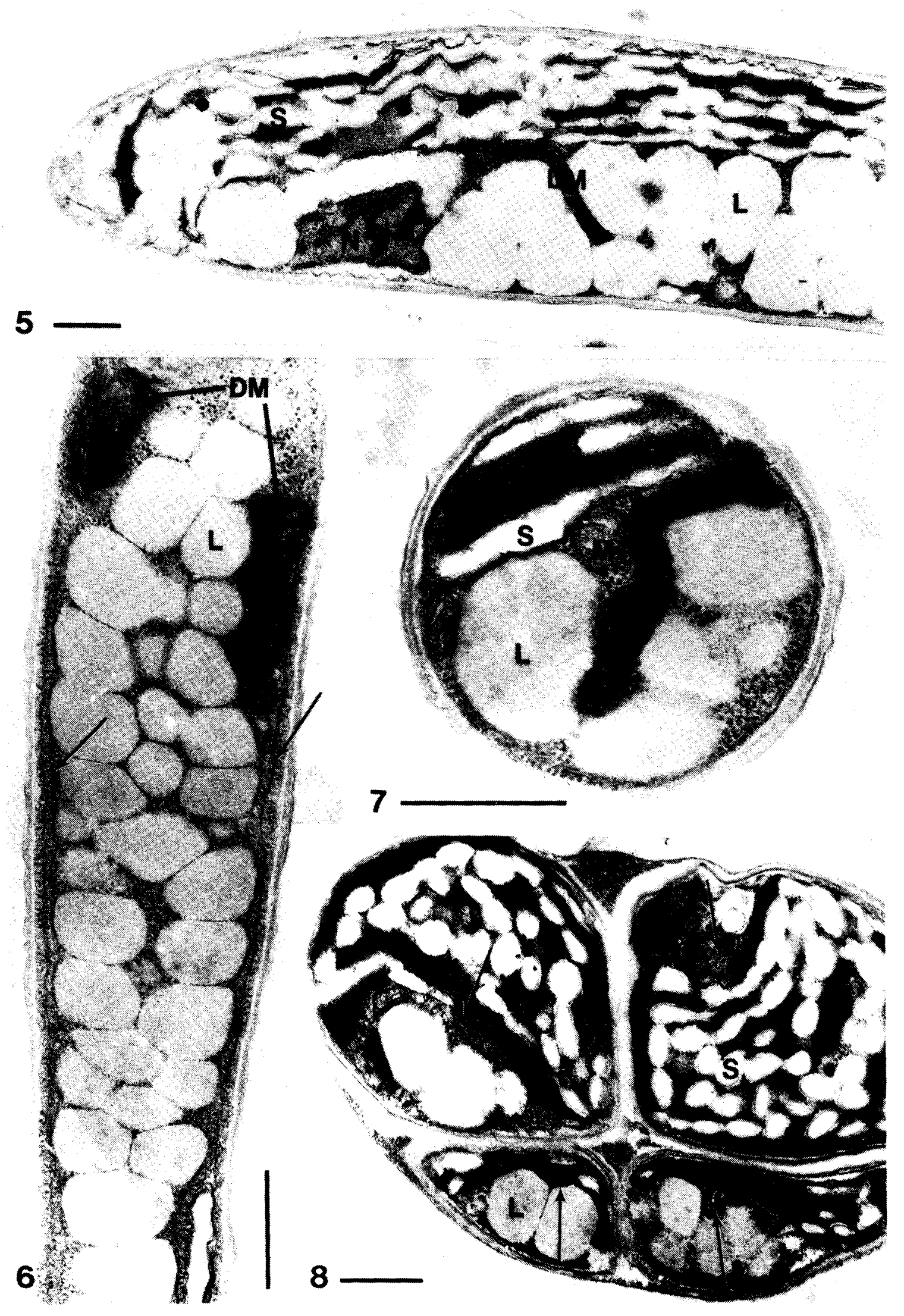

气ิ 


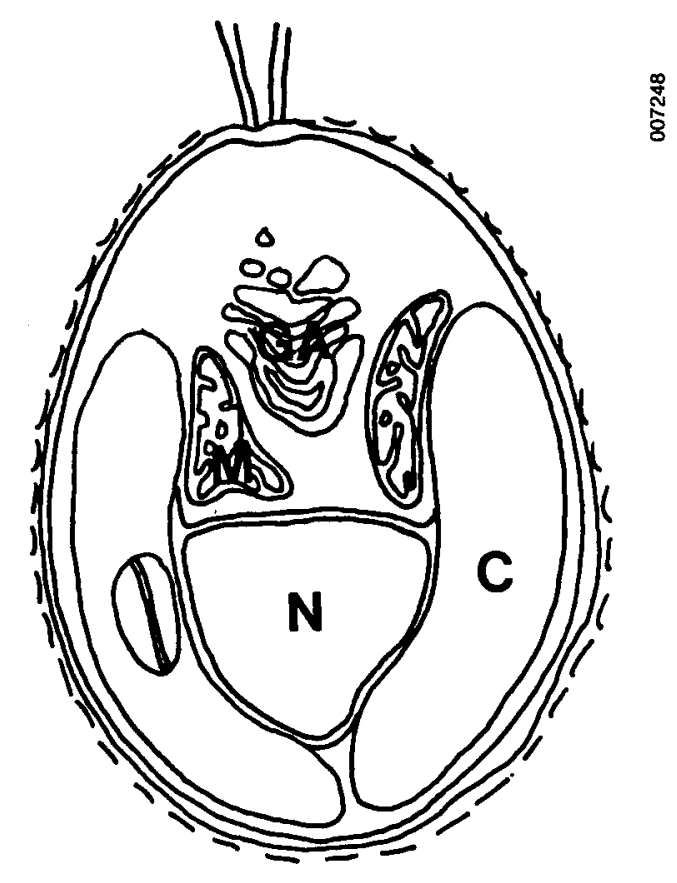

Fig. 9. Diagram showing the general pattern of organization of the Isochrysis cell. $N=$ nucleus, $C=$ chloroplast, $M=$ mitochondrion, $G A=$ Golgi apparatus. 
is covered with a layer of scales (Fig. 10, arrows), and just beneath the plasma membrane is a vesiculate region which, at times, contains a variety of particulate matter and globules (e.g., see Figs. 12, 13, and 15). Epifluorescence microscopy reveals the presence of small oil droplets (usually two) in the posterior region of healthy cells (not shown).

When Isochrysis cells are deprived of nitrogen (Figs. 15-17), the volume occupied by the chloroplasts appears to decrease, but this has not been confirmed by morphometric methods. The size and number of lipid droplets, which are usually very closely associated with the mitochondria (Figs. 12 and 16), increase dramatically. Occasionally, crystalline structures are associated with large lipid droplets (Fig. 17). In the present study we11-preserved Isochrysis cells with large amounts of accumulated lipid were few. Figure 15 shows a typical cell from a nutrient-stressed culture; the contents of over half the cell appear granular, a characteristic not usually associated with fixed lipid droplets. Light microscopy of this culture indicated, however, that this granular substance may indeed be lipid.

\section{Nannochloropsis salina}

The cells of Nannochloropsis contain one large parietal chloroplast with thylakoids in groups of three extending the length of the organelie (Fig. 18). The thylakoids are not organized into grana. In exponentially growing populations, few inclusions occur within the chloroplast (Figs. 18-21). The nucleus $(N)$ is centrally located adjacent to the chloroplast (Fig. 19), and one large mitochondrion (M) 
Figs. 10-14. Cells from a nutrient-sufficient culture of Isochrysis aff. galbana. Scale bars $=0.5 \mu \mathrm{m}$.

Fig. 10. The nucleus (N) lies within the cup formed by the chloroplasts (C). A Golgi apparatus (GA) occupies an anterior position. Scales (arrows) cover the cell surface.

Fig. 11. This longitudinal view shows a dorsiventral flattening of the cel1. A pyrenoid (arrow) is located within the chloroplast.

Fig. 12. A mitochondrion $(M)$ is located near both a chloroplast (C) and a lipid droplet (L). Periplasmic space $\left(^{*}\right)$ contains globules.

Fig. 13. Detail of a pyrenoid (P) within a chloroplast. A double thylakoid lamella runs through its length.

Fig. 14. A mitochondrion (M) maintains a close association with the adjacent chloroplast (C). 


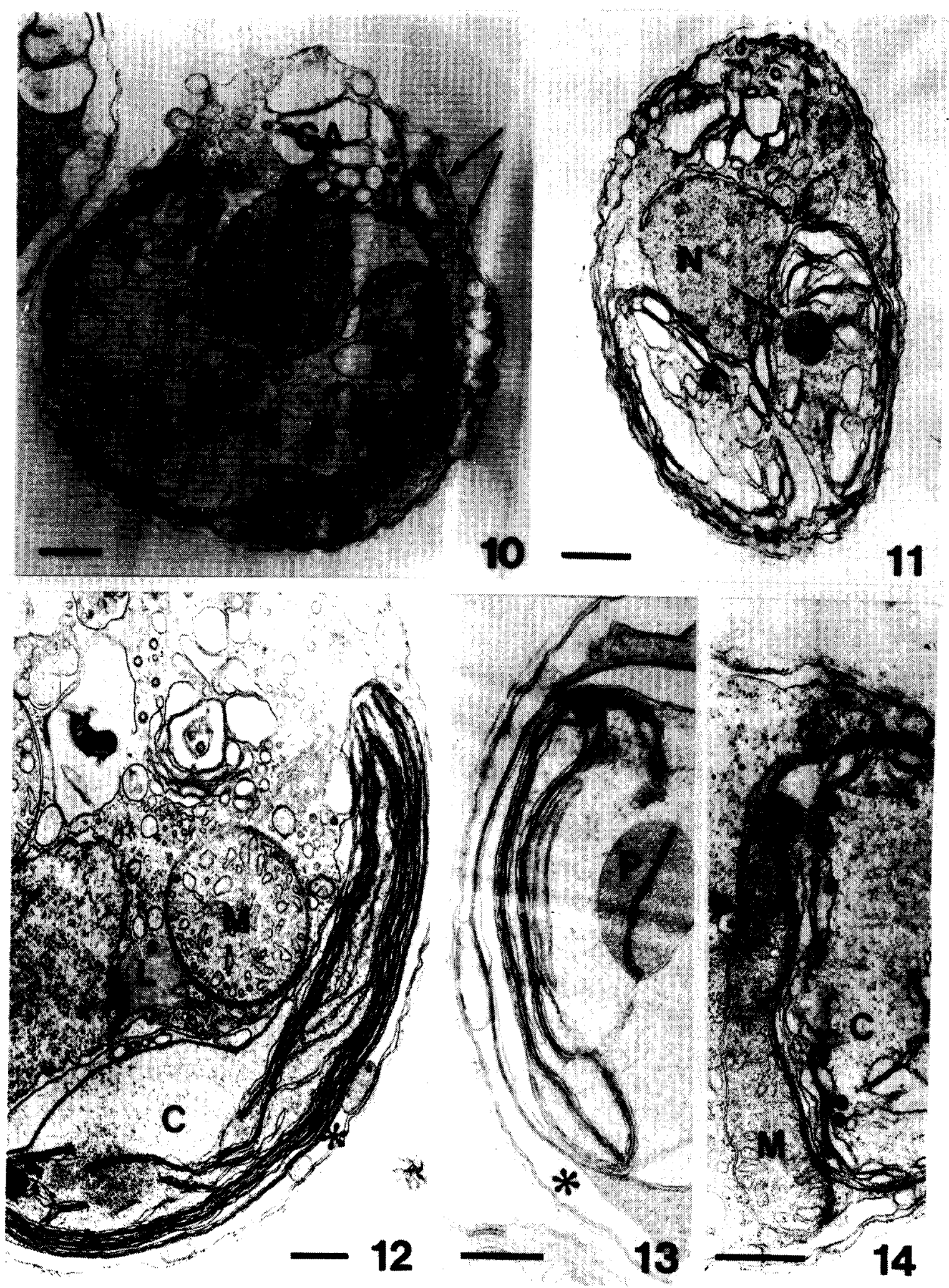


Figs. 15-17. Nutrient-stressed cells of Isochrysis aff. galbana. Scale bars $=0.5 \mu \mathrm{m}$.

Fig. 15. Most of the volume of this cell is occupied by a granular material not typical of lipid. Typical lipid droplets (L) lie adjacent to the chloroplast (C). The periplasmic space $\left(^{*}\right)$ is filled with small droplets.

Fig. 16. A lipid droplet (L) is closely associated with both a chloroplast (C) and a mitochondrion (M).

Fig. 17. Crystalline structures (arrow) are associated with a large ifpid droplet $(L)$. 


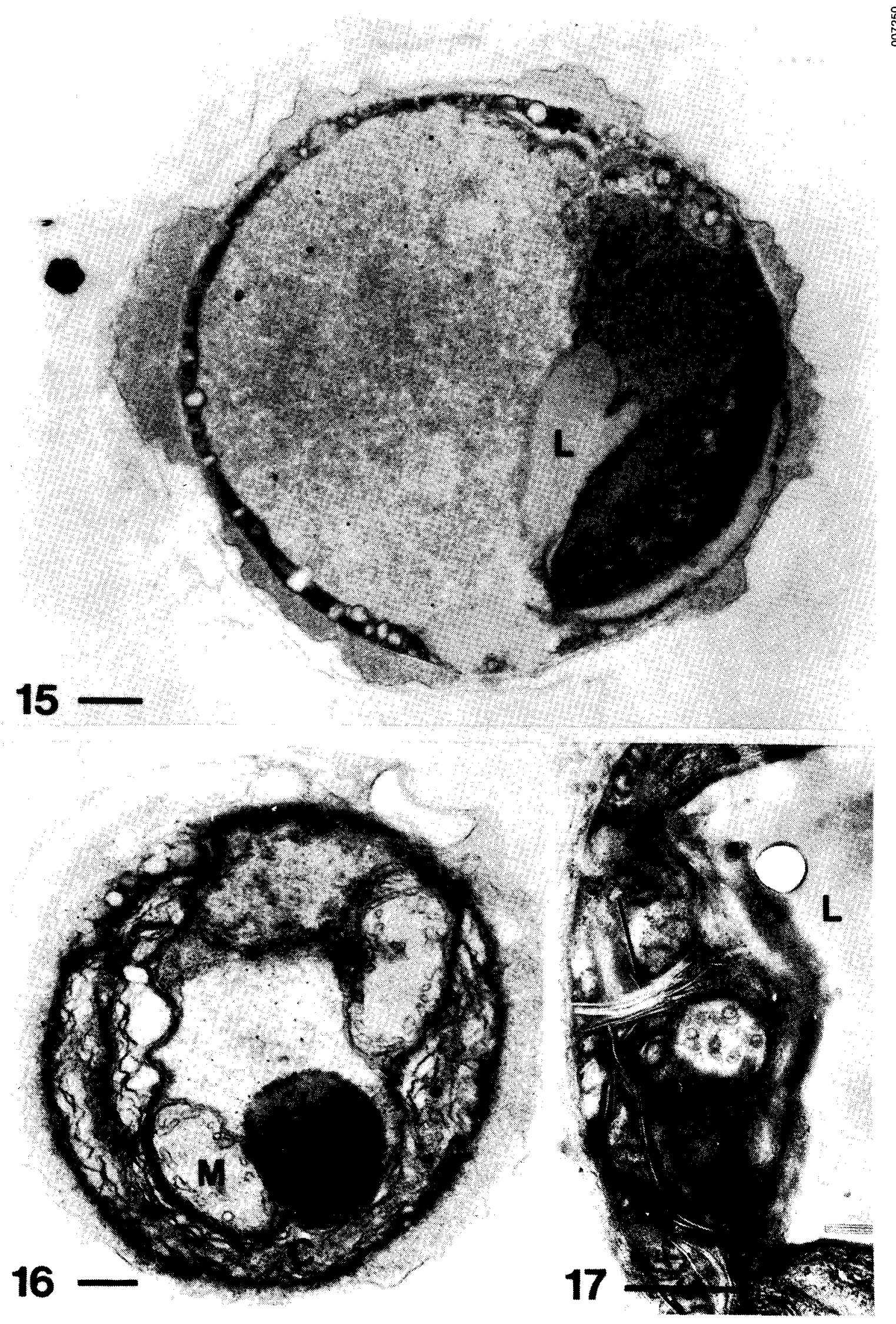


Figs. 18-21. Cells from a nitrogen-sufficient culture of Nannochloropsis salina. Scale bars $=0.5 \mu \mathrm{m}$.

Fig. 18. Parallel lamellae extend the length of the single chloroplast. Multiple layers of a mucllagenous substance (arrow) cover the cell.

Fig. 19. The prominent nucleus $(N)$ is adjacent to both a chloroplast $(C)$ and a mitochondrion $(M)$, the latter flanked by lipid droplets (L).

Fig. 20. A close spatial relationship occurs between the mitochondria $(M)$, chloroplast $(C)$, and lipid droplets (L).

Fig. 21. Multiple small lipid droplets (L) occur in most cells. 

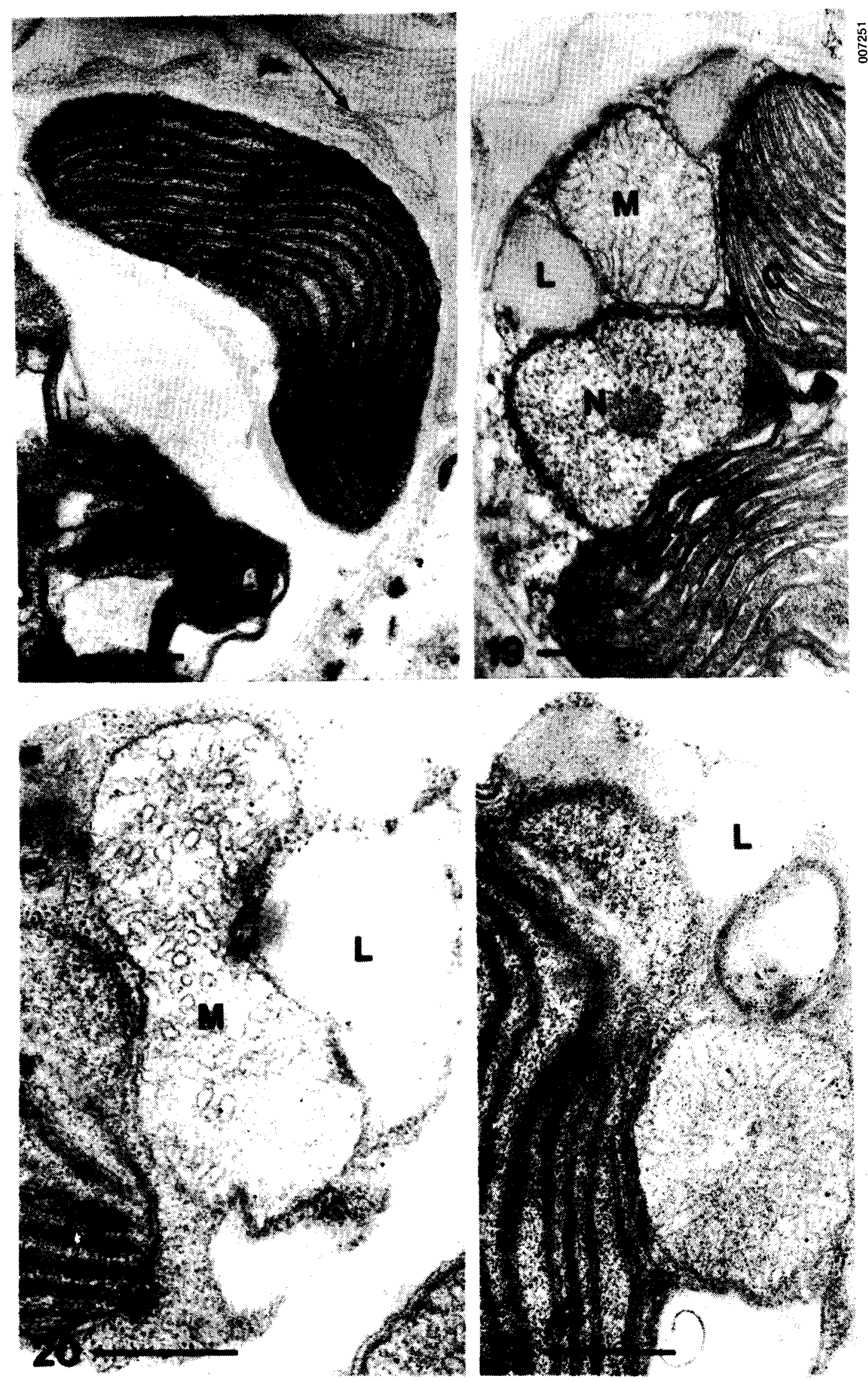
occupies inuch of the remainder of the cell (Fig. 20). Lipid droplets, usually adjacent to the mitochondrion, are common (Figs. 19-21), even in exponentially growing populations. One or more vesicles with finely lamellate contents are also present (Solomon 1985). Cells are typically surrounded by multiple layers of an electron-lucent substance (Fig. 18).

In comparison with healthy cells, nutrient-stressed cells contain more cytoplasmic lipid droplets (Figs. 22-25). Within the chloroplasts of nitrogen-deficient cells, small lipid droplets (plastoglobuli, P) are numerous (Fig. 24), and vesicles often disrupt the orderly arrangement of thylakoids (Figs. 22-25). Crystalline structures are sometimes associated with the borders of the lipid droplets (Fig. 25).

This species is very difficult to fix and embed effectively, a problem also noted by other researchers (Hibberd 1980; Lubian 1982). The cells, which appear ovoid under light microscopy, are usually shrunken and angular when sectioned. In addition, they tend to fall out of the embedding resin when sectioned, indicating incomplete penetration of the resin. The use of Araldite-EmBed resin, instead of Spurr's, improves resin penetration.

FLOW CYTOMETRIC ANALYSIS AND SORTING

A flow cytometer measures the light scattered or emitted by individual cells as they pass single file through the beam from a laser light source (see Appendix for more information on the instrumentation and the nature of the data collected). Light is scattered differently depending on the size, shape, and refractive properties of the cell, 
for example. Light can also be emitted either by the fluorescence of a naturally occurring fluorophore or by fluorescent dyes which are absorbed by specific cellular compounds .

In initial experiments, when a lipid-specific fluorescent stain was not available, cultures were analyzed using forward and right-angle scatter to indicate cell size and morphology respectively. It was expected that the internal morphology of cells, as measured by right-angle scatter, might vary with intracellular lipid level (i.e., many small, highly refractive droplets could be differentiated from one large oil body). Initial analysis of a one-month-old culture of Isochrysis (nitrogen-depleted, judging from the color of the culture) showed that there were two distinct populations of cells (Fig. 26a), one consisting of cells producing little right-angle scatter but in a wide range of sizes, the other being small cells producing a broad range of right-angle scatter. A corresponding Nannochloropsis culture did not reveal a similar pattern (Fig. 26b).

To determine whether the variation observed in right-angle scatter was related to lipid content, nutrient-stressed and exponentially growing populations of Boekelovia (Chryso F-l) were analyzed using the same parameters. Figure 27 shows the right-angle histograms for these cultures; a doubling of the mode is associated with the nutrient-stressed cells, suggesting that right-angle scatter correlates directly with intracellular lipid content. This correlation was not observed in the glutaraldehyde-fixed cells. 
Figs. 22-25. Nutrient-stressed cells of Nannochloropsis salina. Scale bars $=0.5 \mu \mathrm{m}$.

Fig. 22. Large lipid droplets (L) surround mitochondrion (M).

Fig. 23. Small lobe of chloroplast (C) extends into mitochondrial invagination. A large lipid droplet is adjacent to both the mitochondrion (M) and chloroplast.

Fig. 24. Plastoglobuli (P) were common within the chloroplasts of nutrient-stressed cells.

Fig. 25. Crystalline structures (arrow) were sometimes associated with large lipid bodies. 



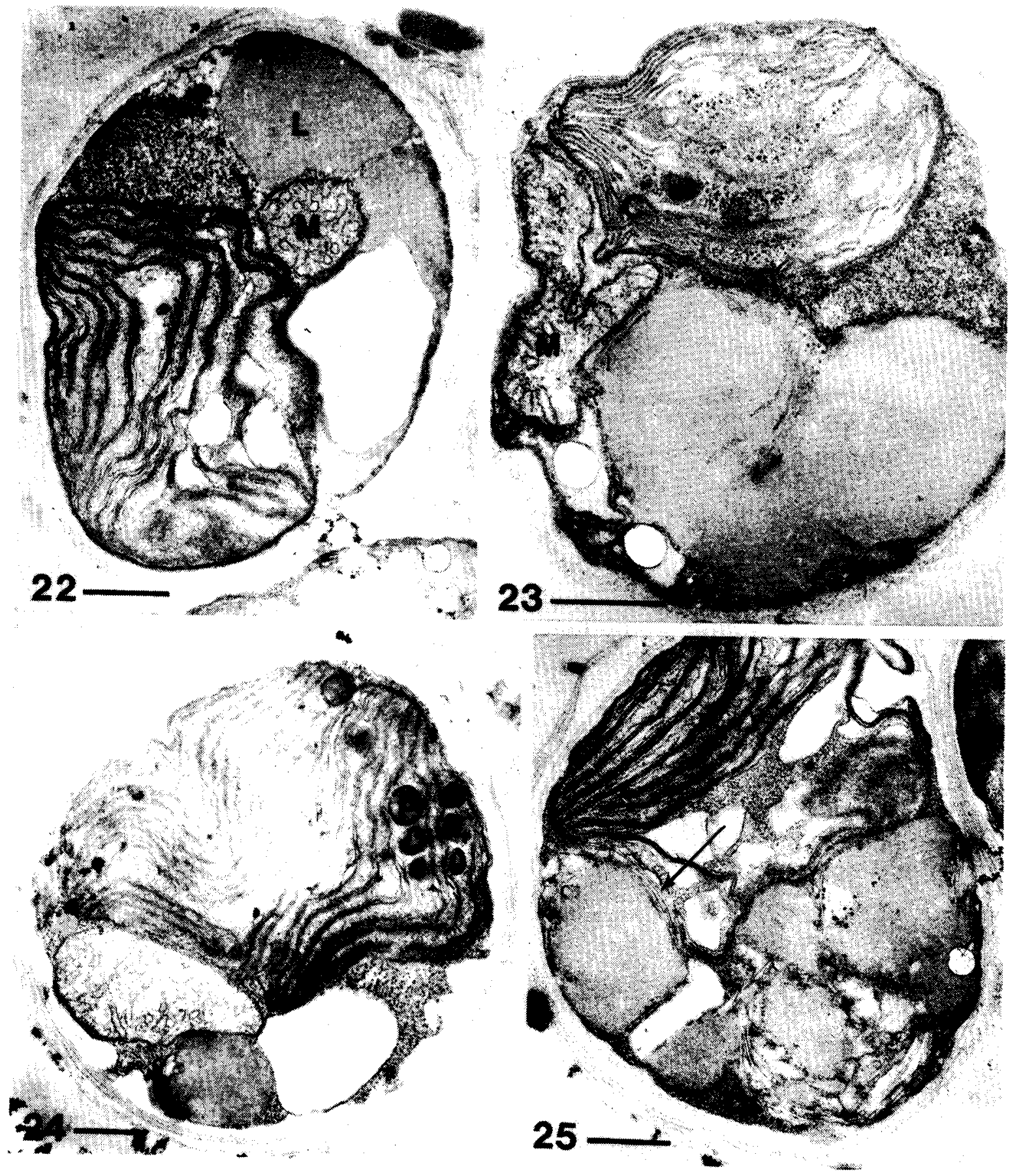

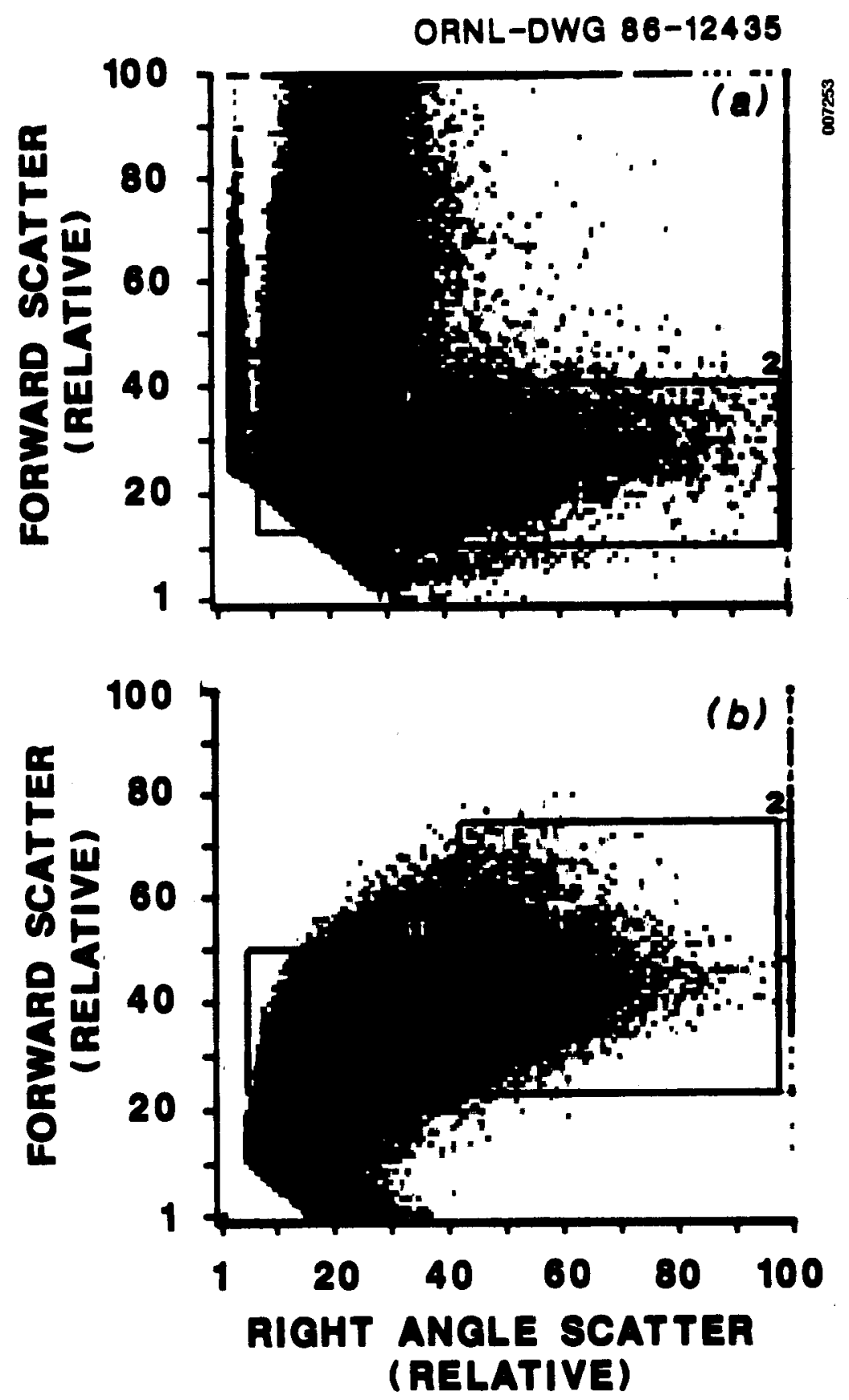

Fig. 26. (a) FCM analysis shows relationship between forward and right-angle scatter in an aged Isochrysis culture. Density of each point represents the number of cells in which that combination of parameters was found. Forward scatter indicates cell size and right-angle scatter is correlated with internal morphology. Note: Regions 1 and 2 were used fop sopting; they do not correspond to the two populations mentioned in the text. (b) Cytograph shows relationship between cell size (forward scatter) and internal morphology (right-angle scatter) in an aged culture of Nannochloropsis salina. 
ORNL-DWG 86-12434


Fig. 27. Histograms showing frequency of internal morphology variations in Boekelovia: (a) in an exponentially growing culture and (b) in a nutrient-stressed culture. Note change in shape of curve and location of mode. 


\section{Nile Red Studies}

Analys is of stressed and unstressed Boekelovia cultures. When the lipid-specific, vital fluorescent dye, nile red, became available it was used to measure cellular lipid content directly. The measurement of chlorophyll autofluorescence in addition to nfle red lipid fluorescence ensured that only those lipid-containing cells with intact chloroplasts would be included in the anaiysis. Boekelovia was stained with both acetone and heptane preparations of nile red and the results were compared using epifluorescence microscopy. The considerable spectral overlap between the autofluorescence from chlorophyll and nile red dissolved in acetone indicated that heptane was the more suitable solvent.

Initial work with nile red utilized exponentially growing and nutrient-stressed cultures of Boekelovia. To determine the extent of background fluorescence in the yellow-green region of the spectrum, where nile red emission peaks, stained preparations of exponentially growing and nutrlent-stressed Boekelovia cultures were compared with unstained ones. Littie background fluorescence occurred in the exponentially growing culture (Fig. 28b); higher levels occurred in the nutrient-stressed culture (Fig. 28d). Epifluorescence microscopy confirmed this phenomenon: in the absence of nile red, healthy cells had only the faintest yellow-green fluorescence, but in unhealthy cells (those with little or no red chlorophyll fluorescence), the plasma membrane and nuclear region emitted a more pronounced yellow-green 1 ight. 


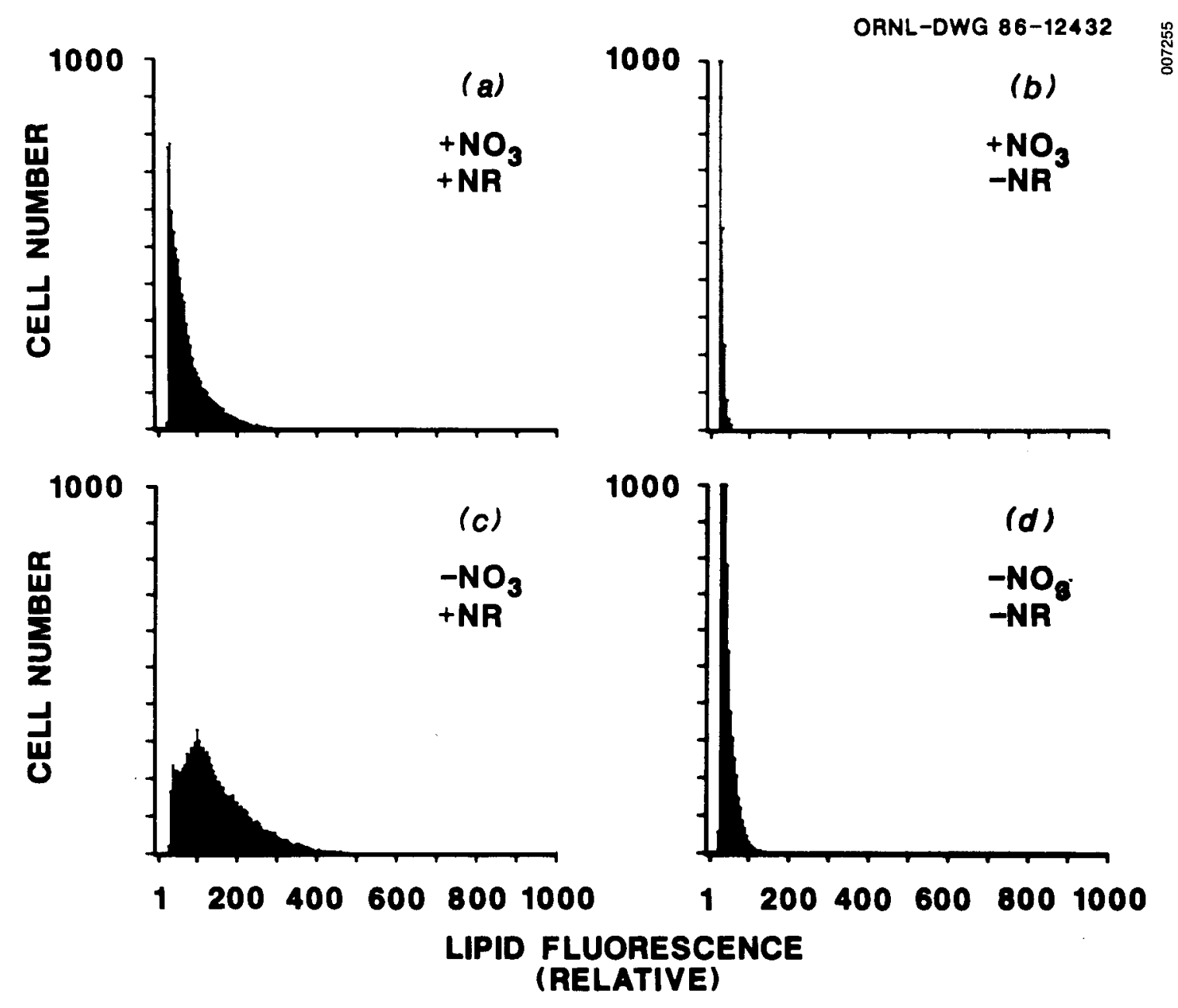

Fig. 28. Histograms for baseline studies of nile red fluorescence in Boekelovia. (a) Nutrient-sufficient culture stained with nile red. (b) Unstained nutrient-sufficient culture. (c) Nutrient-stressed culture stained with nile red. (d) Unstained nutrient-stressed culture. 
Comparison of healthy and stressed Boekelovia cells stained with nile red revealed higher intensities of yellow-green fluorescence in the stressed cells, indicating correspondingly higher lipid levels (cf. Figs. 28a and c). Under epifluorescence microscopy, two or three small lipid droplets were found in the posterior portion of unstressed cells. In contrast, inost cells of the stressed culture had five or six larger droplets, visually confirming a difference in lipid levels. Suitability of Isochrysis, Ankistrodesmus, and Nannochlorops is cultures for FCM. All three microalgal species examined by electron microscopy were initially considered to be candidates for FCM. Ankistrodesmus was determined, a priori, to be unsuitable because of its cell shape; spherical particles are most easily handled by the flow cytometer; any deviation from this shape makes the process more difficult (Personal Communication, R. Mann, Biology Division, ORNL, to J. A. Solomon). In addition, Ankistrodesmus cells are at the upper size limit $(50 \mu \mathrm{m})$ of particles that could be handled by the instrument.

Nannochloropsis cells were entirely appropriate, in size and morphology, for FCM, but healthy cells failed to take up the nile red dye. Epifluorescence microscopy revealed that the only cells emitting yellow-green fiuorescence were dead (those lacking the red fluorescence of chlorophy 11). For this reason, flow cytometric analys is of Nannochloropsis was not pursued.

Isochrysis cells were easily measured and sorted using FCM. They have a compressed spherical shape of approximately 5 um diameter, 
thus meeting the morphological requirements. In addition, the cell covering consists of numerous separate scales which apparently do not inhibit uptake of the dye.

Analysis and Sorting of Isochrysis. FCM analys is of a nutrient-stressed Isochrysis culture showed a 20-fold range in lipid content ( 40 to 800 relative fluorescence units; Fig. $29 \mathrm{~b}$; see Appendix for discussion of relative fluorescence units). From this parent population, high and low lipid subpopulations were selected and sorted (regions 1 and 2, Fig. 29a). The high lipid fraction (region 1) was placed in a nitrogen-sufficient medium and grown for one month, after which time it was again subjected to nitrogen deprivation. A cytograph of the resulting subpopulation is shown in Fig. 29c. Because the scales of relative lipid fluorescence were not identical in this experiment (differing by roughiy 20\%), a quantitative comparison between the parent and daughter populations cannot be made (see Appendix for discussion of this problem). Comparison of the cytograph patterns (Figs. 29a and c) and the lipid histograms (Figs. 29b and d) of daughter and parent populations, however, shows several interesting features. First, the range of lipid content of the sorted cells was much greater than that of cells in the parent population. Also, the shapes of the lipid histograms for the two fractions (Figs. 29b and d) are markedly different, with the original culture having one high peak skewed to the left and low variance, and the enhanced culture having a nearly uniform distribution, with no significant peak and a high variance. Although the scales are not identical, it is obvious from 

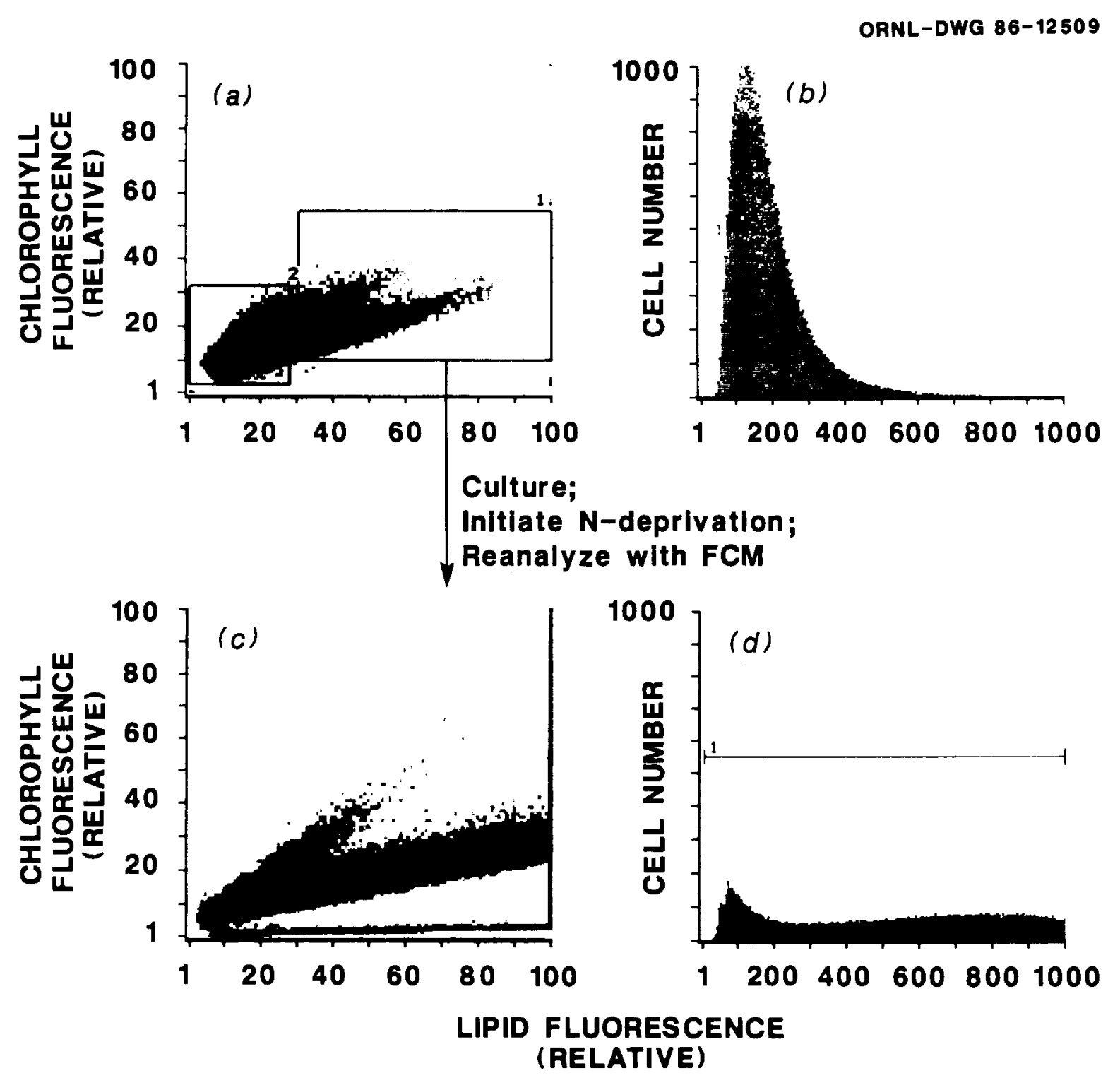

Fig. 29. FCM analysis and sorting of a nutrient-stressed Isochrysis culture. (a) Box 1 on two-dimensional cytograph delimits high-lipid region of parent population that was sorted. (b) Lipid frequency distribution of entire parent population shown in (a).

(c) Cytograph of daughter population derived from region 1 in (a) after cells were cultured, stressed, and reanalyzed. (d) Lipid frequency distribution of daughter population shown in (c). 
the histograms (Figs. $29 b$ and $d$ ) that the lipid content, as measured by nile red fluorescence, is much higher in the daughter population than in the parent one.

Two additional experiments were performed in an attempt to replicate the findings just discussed. In both, $500 \mathrm{ml}$ of a nitrogen-sufficient Isochrysis culture was centrifuged, divided into two equal fractions, and placed into nitrogen-deficient media (Fig. 30). The sorting procedure was replicated, producing four daughter populations from each parent culture (two each from the low and high lipid regions). A total of eight cultures thus resulted from each of these experiments. The daughter populations were cultured in nitrogen-sufficient medium long enough to produce adequate growth, centrifuged, and the pellet transferred to nitrogen-deficient medium prior to reanalysis with FCM after about one week. Within each experiment, the photomultiplier gain settings were heid constant, making the scales equal in all resulting cytographs.

In the first of these experiments, the two regions to be sorted included cells that were (1) low in lipid, relatively high in chlorophyll and (2) high in lipid, relatively low in chlorophyll (Fig. 31a). Unfortunately, mechanical failure of the culture chamber resulted in loss of the nitrogen-deficient daughter cultures. In transferring the daughter cultures to nitrogen-deficient media, pellet formation of the cells had been very poor, numerous cells being retained in the supernatant. This supernatant fraction had also been cultured was still available. Because these cells had been derived from the same region of the parent culture as had the pelleted cells, 


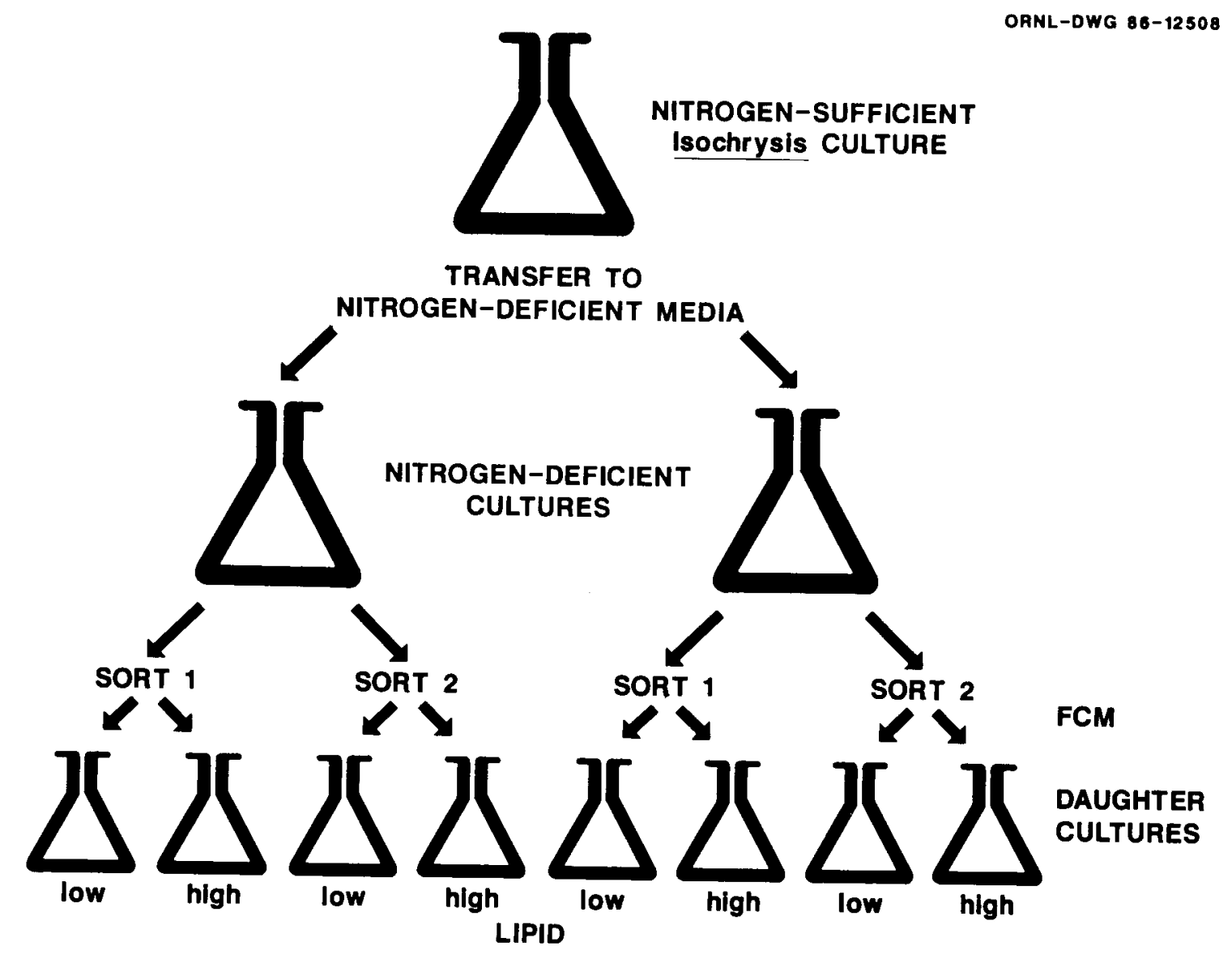

Fig. 30. Experimental design of two Isochrysis sorting experiments, designated sorts 5 and 6 in text. A nutrient-sufficient culture was divided into two fractions and deprived of nitrogen. Using FCM, high and low lipid regions were sorted from each fraction in replicate, cultured, subjected to nutrient stress, and reanalyzed. 
and thus represented the same chlorophyll:1ipid relationship, they were used instead of the pelleted cells. The cultures were grown for one month, transferred to nitrogen-deficient media, and then reanalyzed one week later using FCM. The results are presented in Fig. 32 (sorts $5 \mathrm{~A}$ and $5 B$ ), and cytographs of sort 5A, replicate 2 are shown in Figs. $31 \mathrm{~b}$ and $31 d$. The cultures were again reanalyzed five days later, producing the cytographs shown in Figs. $31 \mathrm{c}$ and $31 \mathrm{e}$.

In the second experiment, the regions to be sorted were selected solely on the basis of lipid content. Because chlorophyll and lipid contents are correlated, however, region 1 contained low lipid, low chlorophyll cells and region 2 contained high lipld, high chlorophyll cells (Fig. 33a). The results are shown in Fig. 32 (sorts $6 A$ and $6 B$ ) and in the cytographs in Fig. 33 (which corresponds to sort 6B, replicate 1 of Fig. 32 ).

The results of these two experiments were not consistent. Distinct differences in lipid content between the high and low lipid daughter populations were found in only two of the eight cases $(5 A-2$ and $6 \mathrm{~B}-1$, discussed above). It was observed that, whenever a high lipid content developed in a culture, it was accompanied by a reduction in the chlorophyll:lipid $(C: L)$ ratio. Because the scales are relative, the exact values for the ratio reduction have no particular significance. In Figs. 31 and 33, a line is drawn on each cytograph representing a relative C:L ratio of $1: 1$. In some cases (e.g., Fig. $32,5 B-1)$, the $C: L$ ratio was reduced in both fractions but high levels of lipid did not develop in either. Conversely, in 6A-1 (Fig. 32), high lipid levels developed in both "high" and "low" lipid 
Fig. 31. FCM analysis of Isochrysis sort 5A, replicate 2. The $1: 1$ ratio of chlorophyll to lipid is designated by the line drawn on each cytograph. (a) Cytograph of parent population showing low lipid (1) and high lipid (2) sorting regions. (b) Low lipid daughter population derived from region 1 of (a) following two months of growth and $6 \mathrm{~d}$ of nitrogen deficiency. (c) Same as (b), 5 d later. (d) and (e) High lipid daughter population derived from region 2 of (a), following growth for two months followed by $6 \mathrm{~d}$ (d) followed by $11 \mathrm{~d}$ (e) of nutrient-stress. Note relationship of populations to the $1: 1 \mathrm{C}: \mathrm{L}$ ratio. 

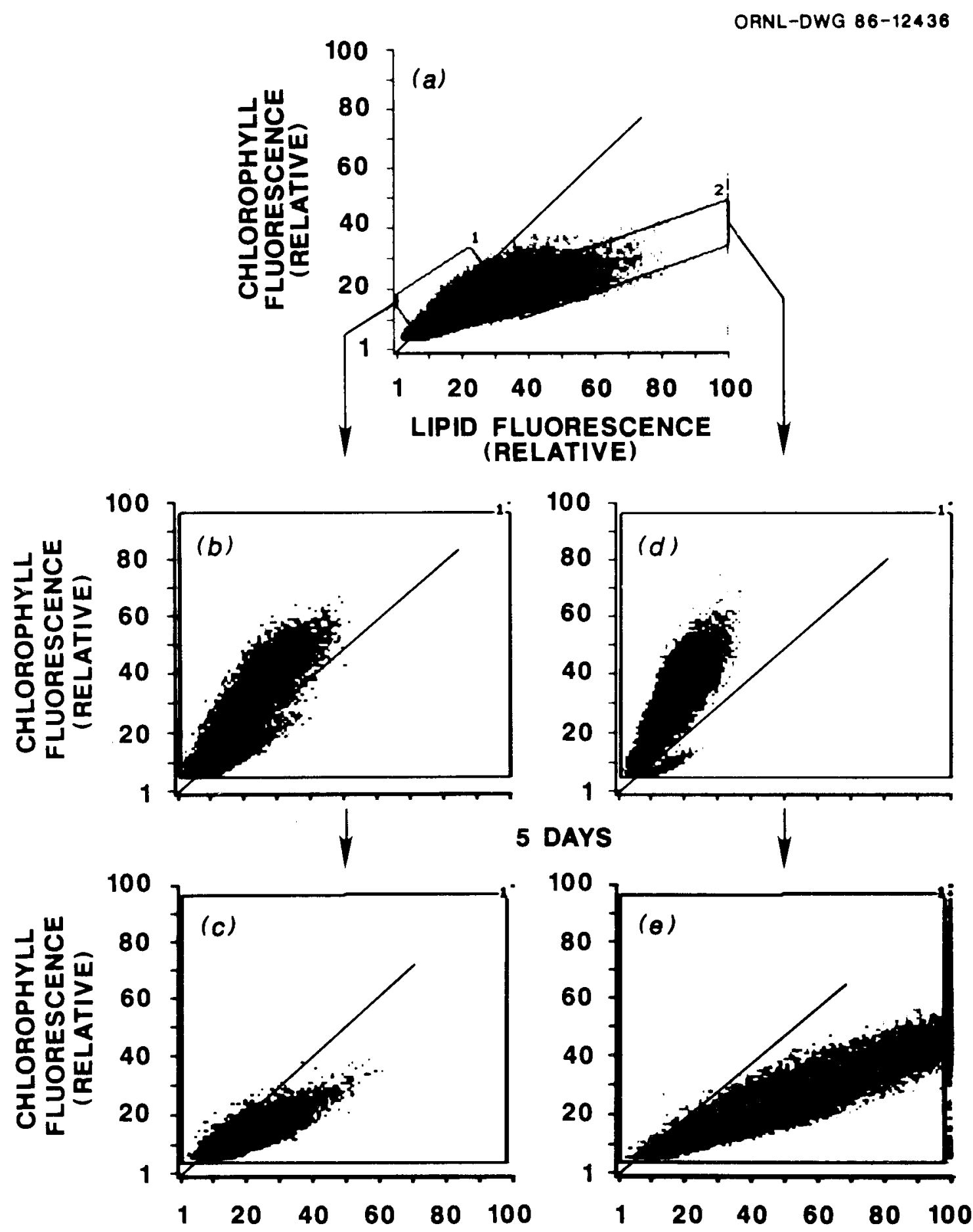

LIPID FLUORESCENCE

(RELATIVE) 




Sample Number

Fig. 32. Reanalysis of daughter populations from sorts 5 and 6 (compare with Figs. 31 and 33 ). Population represented by shaded bars are derived from high lipid fraction of sort, unshaded from low lipid fraction. The + sign above bar designates a population in which the chlorophy11:1ipid ratio was reduced at the time of measurement; a - sign indicates the ratio was not reduced. As explained in the appendix, the four highest values for mean lipid content are underestimated due to many cell measurements being off the scale. 


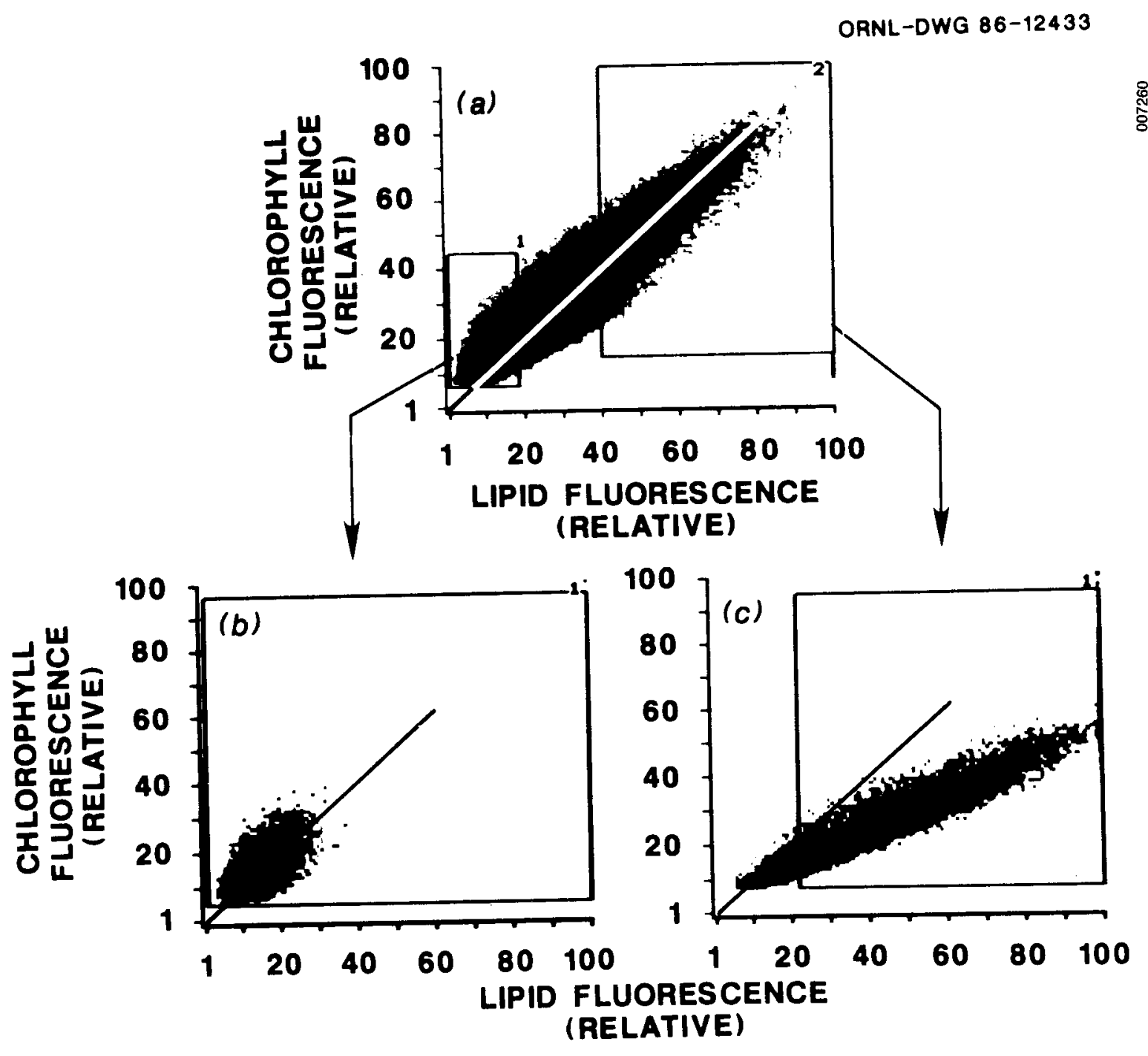

Fig. 33. FCM analysis of Isochrysis sort 6B, replicate 1. The $1: 1$ ratio of chlorophyl1 to lipid is designated by the line drawn on cytographs of daughter cultures. (a) Cytograph of parent population showing low lipid (1) and high lipid (2) sorting regions. (b) and (c) Low and high lipid daughter populations derived from regions 1 and 2 , respectively, of (a) following one month of growth and $7 \mathrm{~d}$ of nutrient-stress. 
daughter cultures, and in both cases the $C: L$ ratio was reduced. In some cultures, the $C: L$ ratio did not drop within the duration of the experiment (e.g., 5B-2, Fig. 32).

In Figs. $31 \mathrm{~b}$ and $31 \mathrm{~d}$, two separate populations are seen, a larger one above the 1:1 line and a much smaller one below the line. This phenomenon was seen regularly throughout the study (see also Figs. 29a and $c$ ).

\section{DISCUSSION}

For each algal species examined ultrastructurally, a series of fixations was performed through time, beginning on the day the cells were transferred to nitrogen-deficient conditions and ending when the color of the culture indicated that lipid accumulation had been accomplished (10-13 d Tater). Ultrastructural comparisons of exponentially growing and nutrient-stressed cells of all three species examined showed that lipid was always accumulated in the cytoplasm. Occasionally small lipid droplets formed in the chloroplast, but these were more electron-dense than the cytoplasmic lipid droplets and never constituted a very large quantity of lipid.

The repeated occurrence of the mitochondrion in close association with both lipid droplets and the chloroplast was noted in all three species and may indicate a close metabolic relationship among these three organelles. Two other structures which may be related to lipid accumulation, based on spatial organization, are the presumptive crystalline structures seen in Nannochloropsis and Isochrysis and the 
double membrane structure in Ankistrodesmus. These two structures may, in fact, be closely related to one another, because the crystalline structure may be interpreted as being a series of membranes which have become rigid and separated from one another, perhaps as an artifact of fixation. The morphological similarity between the double membrane structure of Ankistrodesmus and the carotenoid-containing chromoplasts of flower petals suggests a lipid-accumulating function for that organelle. The extent to which any of these organelles are actually involved in lipid accumulation, however, remains to be determined.

Underlying the time series approach used in this ultrastructural study were the assumptions that lipid accumulation is a function of the culture (i.e., of the population as a whole) and that the process takes place over a period of 7 to $10 \mathrm{~d}$. Throughout these time series, cultures were monitored using nile red and epifluorescence microscopy. As determined with epifluorescence microscopy, the most noticeable difference in Ankistrodesmus cultures, which were monitored most closely from day to day, was the number of cells in which lipid had accumulated, rather than the quantity of lipid per cel1. These microscopic observations suggest that a more complete understanding of microalgal lipid accumulation might be achieved by considering the process at the level of the individual cell rather than at the level of the entire culture, as discussed below.

A MODEL FOR LIPID ACCUMULATION AT THE POPULATION LEVEL

Results from the present study indicate that an individual cell is either accumulating lipid or it is not (i.e., the "lipid trigger" works 
at the cell, not the culture or population, level). Although this idea certainly is not new, there have been few tools that allow the interpretation of population changes as the result of the behavior of individual cells. Flow cytometry now provides that capability. It appears from this study that if a cell is accumulating lipid, then the process is rapid, requiring 1 to 2 d for completion. Some cells respond to the lipid trigger more readily than others, accounting for the 7 to $10 \mathrm{~d}$ needed for maximum lipid accumulation by the population as a whole. The endpoint of a culture (i.e., the point at which maximum lipid has accumulated) reflects the time required for a significant portion of the population to respond. The evidence to support this hypothesis comes from several phases of the present study.

1. Healthy Ankistrodesmus cells contain no lipid droplets. Monitoring Ankistrodesmus lipid accumulation over time, using nile red and epifluorescence microscopy as mentioned above, revealed that the most obvious daily difference was in the number of cells containing lipid droplets, not in the size of the droplets or in the number of droplets per cell, although these also increased. The situation may be different for Isochrysis, because cells of this species in exponential growth phase normally contain two lipid droplets. Under nutrient-stress conditions, lipid accumulation consists of increases in both the size and number of droplets. Because Nannochloropsis does not take up nile red, comparable observations were not made on that species. 
2. Transmission electron microscopy (TEM) proved to be a relatively ineffective method for increasing understanding of lipid accumulation in these algal species. TEM examination requires a section that is between 50 and $150 \mathrm{~nm}$ thick, in contrast with a total cell thickness of between 2000 and $5000 \mathrm{~nm}$. Thus, any single section would include, at most, only $8 \%$ of the total cell thickness. Given the current state of knowledge, there is no way of determining the lipid content of the cell that was sectioned, unless the section happens to include lipid droplets. Lipid may be absent in a single cell section because the opposite side of the cell was sectioned (i.e., the side of the cell where lipid droplets were not formed). This difficulty could be overcome by performing serial sectioning, in which the whole cell would be seen; it is a tedious and time-consuming procedure, however. Alternatively, quantitative TEM data can be obtained for cultures of interest by using the technique of morphometry to estimate the total cell volume occupied by lipid. However, this, is a time-consuming, and thus expensive, procedure and deals only with population means.

The biggest difference observed ultrastructurally between cells from day 2 and day 10 in the time series was the number of cells that contained lipid, not in the quantity of lipid they contained. This statement is not based on actual cell counts but rather on the relative difficulty I encountered in finding lipid-containing cells in micrographs made from each of these cultures. 
3. The Isochrysis populations analyzed using FCM were bimodal in comparison with the expected unimodal, approximately Gaussian, distribution of lipid content. One explanation for this biomodality is that the population with the larger chlorophyll:lipid ratio consisted of those cells that had not responded to the lipid trigger, while the population with the smaller $C: L$ ratio contained the cells which were actively accumulating storage lipid. In both cases, of course, a range of lipid content would be expected as a result of natural variation. The existence of two separate populations, however, is not explained by natural variation.

The fact that the higher lipid populations have a lower chlorophy11:lipid ratio implies two things. First, as lipid accumulates, chlorophyll (probably chloroplast volume or thylakoid surface area) remains the same or decreases. There may be a direct conversion of polar membrane lipids of the chloroplast to neutral storage lipids, or there may be a number of intermediate steps. Second, the existence of two discrete populations implies, not a gradual changeover in metabolic processes, but, rather, an either/or situation: a cell is either accumulating storage lipid rapidly or it is not.

\section{IMPLICATIONS FOR THE AQUATIC SPECIES PROGRAM}

The implications of this proposed model for the Aquatic Species Program are significant. The model suggests first that the susceptibility of individual cells to a lipid trigger (i.e., speed of the response) is highly variable and may be an important factor in the 
ultimate lipid yield. For example, in a commercial two-stage venture, the time required for the second stage, lipid accumulation, would be a significant cost factor and, as discussed here, could be improved. Any cells which do not accumulate lipid (or do so only very slowly) will depress the ultimate lipid yield. Thus, to understand lipid accumulation at the level of the entire culture (as would be the concern in a commercial enterprise), we need more information about the distribution of various phenomena within the population, at the level of the individual cell.

Second, the model clarifies the opportunity provided by single-cell-sorting techniques (e.g., FCM). In any natural algal population, there will be a range and a statistical distribution for any given trait (e.g., time of response to lipid trigger, total amount of lipid accumulated, etc.). By means of FCM sorting, we can separate any portion of the population that we can measure, both for enhancing the strain for that given trait and also for experimental uses (i.e., to understand the genetic basis of the trait or to determine its stability). It might be possible to begin with a species or strain that has many desirable growth traits (e.g., temperature and salinity tolerance, competitiveness, etc.) and to identify and remove those few cells having a responsive lipid trigger or a high ultimate lipid content.

Thus, the ability to study the process of lipid accumulation at the cellular level, as well as at the population level, offers both an increased level of understanding as well as the promise of increased commercial potential. 


\section{LITERATURE CITED}

Dubinsky, Z., Berner, T., and Aaronson, S. 1979. Potential of large-scale algal culture for biomass and lipid production in arid lands. Proc. Biotechnol. Bioengin. Symp. 8:51-68. John Wiley \& Sons, Inc.

Graham, C. F. and P. F. Wareing. 1976. The Developmental Biology of Plants and Animals. W. B. Saunders Co., Philadelphia. 393 pp. Greenspan, P., Mayer, E. P., and Fowler, S. D. 1985. Nile red:

A selective fluorescent stain for intracellular lipid droplets.

J. Cell Biol. 100:965-73.

Hibberd, D. J. 1981. Notes on the taxonomy and nomenclature of the algal classes Eustigmatophyceae and Tribophyceae (synonym Xanthophyceae). Brit. J. Linn. Soc. 82:93-119.

Lubian, L. M. 1982. Ultraestructura y pigmentos de algunas Chlorophyceae y Eustigmatophyceae planctonicas de morfologia similar. Coll. Bot. 13(2):873-880.

SERI. 1985. Aquatic Species Program Review. Proceedings of the March 1985 Principle Investigators Meeting. Golden, Colorado, March 1985. SERI/CP-231-2700.

SERI. 1986. Microalgae Culture Collection 1985-1986. Solar Energy Research Institute, Golden, Colorado. SERI/SP-232-2863.

Solomon, J. A. 1985, Ultrastructure evaluation of lipid accumulation in microalgae. in SERI Aquatic Species Program Review op. cit. pp. $71-82$. 
APPENDIX

FLOW CYTOMETRY AND SORTING

Flow cytometry (FCM), measurements of individual single cells are made as the particles pass single file through a beam of intense light (usually a laser source; Figs. $A-1, A-2$ ). When a cell intercepts the laser beam several pulses of light are generated and collected in detection devices around the point of interception.

Information on particle size and internal structure is contained in the intensity of light scattered by a particle into different angles at the same wavelength as the incident light. Although the light scatter pattern of a particle is analytically exactly predictable only for simple geometries (e.g., spheres, cylinders etc.), the light scattered in the forward direction is used in FCM as an indicator of cell size. The intensity of the light scattered at $90^{\circ}$ relative to the incident beam is measured in FCM as an indicator of internal structure (i.e., heterogeneity of refractive index within the particle). Such measurements are very attractive for applications that require cell viability because no staining procedure is necessary.

In addition to elastically scattered light, flow cytometers also measure the intensity of fluorescent light emitted at higher wavelengths than the incident light. Fluorescence may be produced both through natural autofluorescence of cell constituents $[\mathrm{e} . \mathrm{g}$. , chlorophy 11, pyridine nucleotides (Shapiro 1983), etc.] or by the addition of fluorochromes for specific detection purposes. Many 


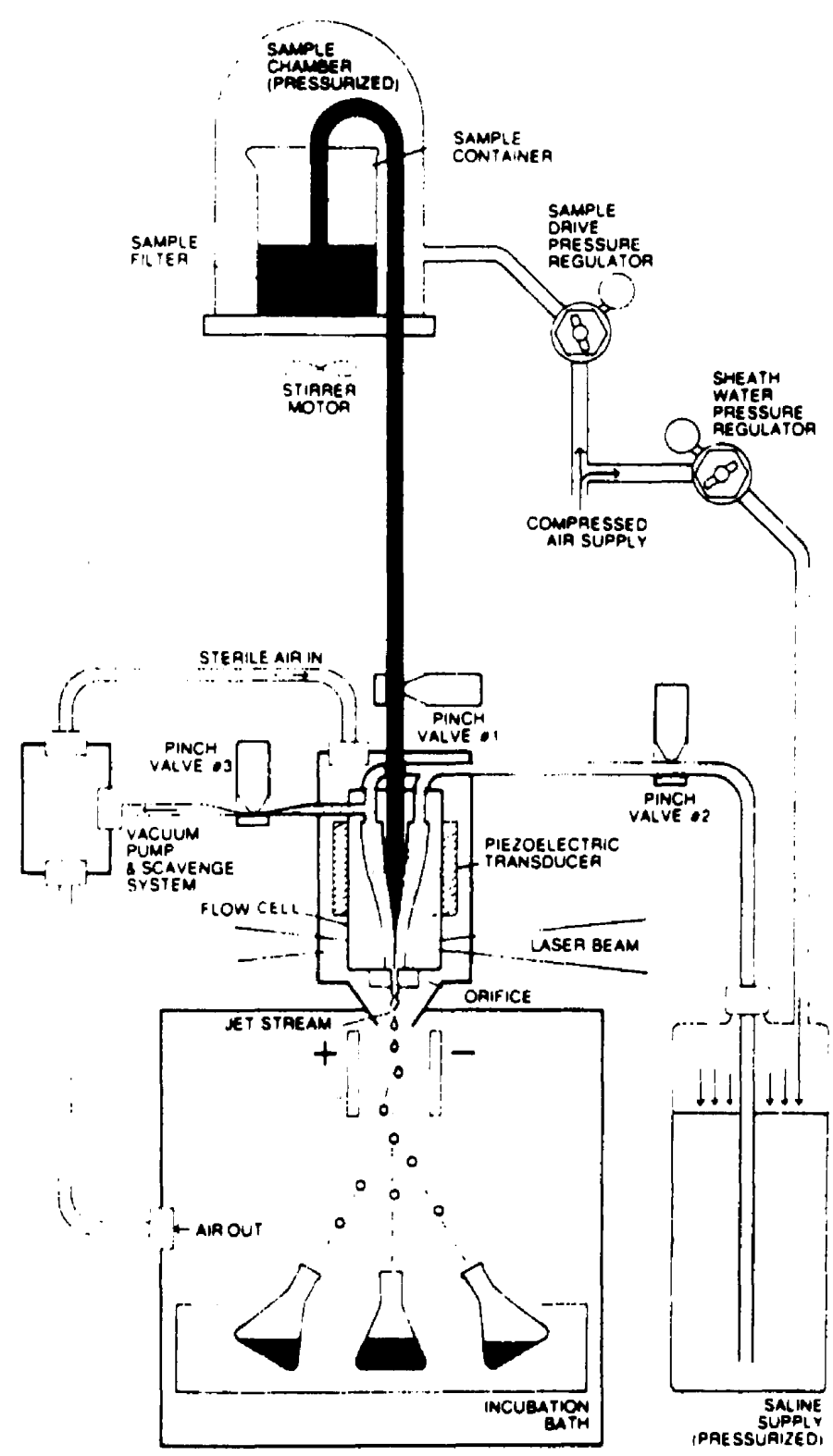

\section{Mociel FC210 Flundics Diagram (System 50 Only)}

Fig. A-1. Schematic fluidics diagram of the Ortho $50 \mathrm{H}$ research flow cytometer. Cells from the sample chamber are made to flow single file through a sensing region where optical signals are generated. Typical flow rates are 500 to 2000 cells per second. A saline solution is used to hydrodynamically focus the suspension of cells into a single line. Sorting of cells is accomplished by using ultrasonic vibrations to break the stream of liquid into tiny droplets, each containing no more than one cell, and an electric charge is applied to droplets of interest. The droplets are then deflected, depending on their charge, by electrically charged plates and are collected in separate vessels. 
OSCILLOSCOPE DISPLAY ON MULT1CHANNEL DISTRIBUTION ANALYZER (GREEN VS. RED FLUORESCENCE)

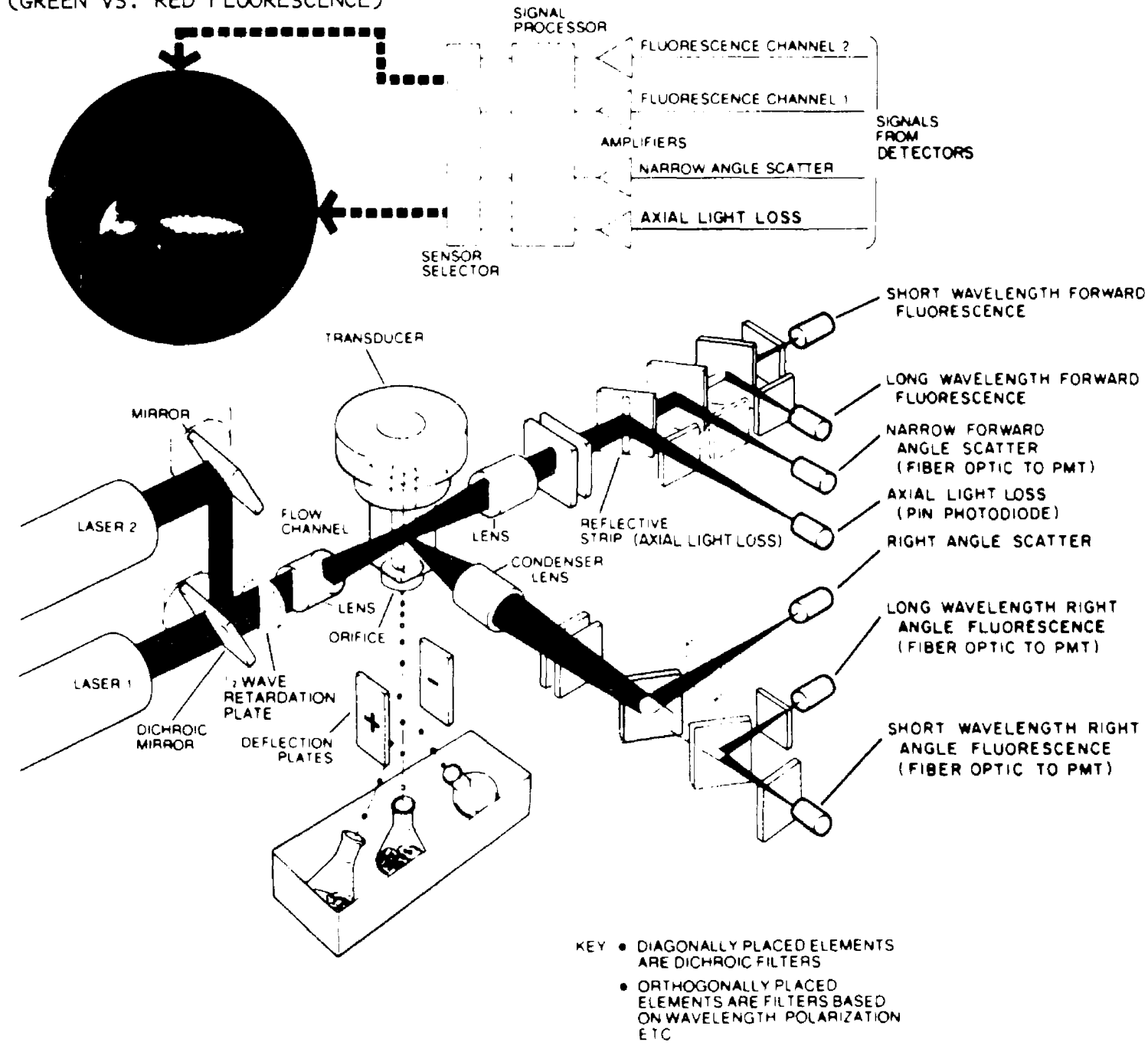

Fig. A-2, Schematic diagram of optical system of the Ortho $50 \mathrm{H}$ research flow cytometer. As cells pass single file through the sensing region, each is illuminated briefly and emits a burst of fluorescence and scattered light. A fraction of the emitted light is captured by a variety of sensors, converted into electrical signals, and fed into various storage and display devices. If the sample is being sorted, decision-making and charging circuits apply an electric charge only to droplets containing the wanted cells. All unwanted cells and empty droplets receive no charge and thus are not affected by the electrically charged deflection plates. 
fluorescent compounds are available to allow FCM measurements of parameters such as cellular DNA and/or RNA content, membrane potential cell surface antigens, etc. By carefully selecting fluorochromes according to their spectral properties, two or more fluorescently labelled cellular compounds can be measured, often with only one laser light source. Flow rates can vary from a few hundred to about 3000 cells/s. Consequently, measurements of 200,000 cells can be made in just a few minutes. This represents an infinite population size for some purposes of statistical comparison.

Some flow cytometers are also capable of physically isolating individual cells of interest as defined by parameters such as DNA content, cell size, etc. This is achieved by applying vibrational energy to the sample stream using a piezoelectric transducer generating ultrasound typically between $32 \mathrm{kHz}$ and $45 \mathrm{kHz}$. The vibrations cause pressure variations along the stream (i.e., localized variations in the flow rate). The liquid in the stream bunches up at certain locations and eventually breaks into droplets. By applying a voltage (sort pulse) to the sample stream at the appropriate time and letting the droplet break off in the region of a ground electrode, droplets containing cells of interest are left with a net charge (induction). They can then be deflected in a subsequent electric field to the left or right, depending on the polarity of the sort pulse. The sort pulse is delayed by the time a cell needs to travel from the location of measurement (i.e., the laser beam) to the point where the droplet breaks off. This time needs to be carefully adjusted before every sorting experiment. Anticoincidence circuitry is available in cell 
sorters to prevent sorting of droplets that contain more than one cell. This is accomplished by suppressing the sort pulse if the above-threshold signal generated by a cell going through the laser beam is longer than a preselected time or if successive signals are separated by less than a preselected interval. This results in high purity of the sort but at the cost of cell yield. Flow rates during sorting need to be somewhat lower than those used for measurement only, with the final yield depending both on the concentration of target cells in the population and the duration of the sorting procedure.

NATURE OF THE DATA

The flow cytometer measures two or more parameters simultaneously for each individual cell of a population. A cytograph, whether reflecting one or two of these parameters, displays the number of cells having a given combination of measurements. The parameters are not measured on an absolute scale unless the instrument has been calibrated using known standards, a procedure which is not usually performed on a routine basis. Thus, a value of e.g., 200 red fluorescence units in these studies does not represent a specific quantity of chlorophyll in a given cell. The scale is linear, however, so that, in a given experiment, a cell with 400 fluorescence units contains twice as much of the fluorescing compound as a cell with only 200 units.

From one experiment to another there will be some scaling variation due to both uncontrolled and operator-controlled factors (e.g., fluctuations in line voltage, adjustments to the photomultiplier gain settings, etc.). In our earliest studies, gain settings were 
adjusted for each experiment separately to achieve the maximum amount of information from each cytograph. Therefore, unless the gain settings were purposely held constant, these experiments cannot be quantitatively compared with one another (i.e., a comparison of means would not be valid). In later experiments the gain settings were held constant to permit comparison. Here, however, the mean fluorescence reading is often not the appropriate statistic because any cell with a measurement greater than 100 on either axis will be recorded as having a value of 100 , falsely skewing the mean. Comparisons of population patterns and of modes are thus preferable to a comparison of means in many cases. 


\begin{tabular}{|c|c|}
\hline \begin{tabular}{|c|l|l|}
$\begin{array}{c}\text { Document Control } \\
\text { Page }\end{array}$ & $\begin{array}{l}\text { 1. SERI Report No. } \\
\text { SERI/STR-231-3089 }\end{array}$ & 2. NTIS Accession No. \\
\end{tabular} & 3. Recipient's Accession No. \\
\hline \multirow{2}{*}{$\begin{array}{l}\text { 4. Title and Subtitle } \\
\text { Ultrastructural and Flow Cytometric Analyses of } \\
\text { Lipid Accumulation in Microalgae }\end{array}$} & $\begin{array}{l}\text { 5. Publication Date } \\
\text { December } 1986\end{array}$ \\
\hline & 6. \\
\hline $\begin{array}{l}\text { 7. Author(s) } \\
\text { J. A. Solomon, R. E. Hand, Jr., R. C. Mann }\end{array}$ & 8. Performing Organization Rept. No. \\
\hline \multirow{2}{*}{$\begin{array}{l}\text { 9. Performing Organization Name and Address } \\
\text { Oak Ridge National Laboratory } \\
\text { Oak Ridge, TN } 37831\end{array}$} & $\begin{array}{l}\text { 10. Project/Task/Work Unit No. } \\
4513.20\end{array}$ \\
\hline & $\begin{array}{l}\text { 11. Contract (C) or Grant (G) No. } \\
\text { (C) DK-4-4142-1 } \\
\text { (G) }\end{array}$ \\
\hline \multirow{2}{*}{$\begin{array}{l}\text { 12. Sponsoring Organization Name and Address } \\
\text { Solar Energy Research Institute } \\
\text { A Division of Midwest Research Institute } \\
1617 \text { Cole Boulevard } \\
\text { Golden. Colorado } 8040]-3393\end{array}$} & $\begin{array}{l}\text { 13. Type of Report \& Period Covered } \\
\text { Technical Report }\end{array}$ \\
\hline & 14. \\
\hline \multicolumn{2}{|l|}{$\begin{array}{l}\text { 15. Supplementary Notes } \\
\text { Technical Monitor: Donna Johnson }\end{array}$} \\
\hline \multicolumn{2}{|c|}{$\begin{array}{l}\text { 16. Abstract (Limit: } 200 \text { words) } \\
\text { Lipid accumulation in three species of microalgae was investigated with flow } \\
\text { cytometry (FCM) and transmission electron microscopy (TEM). Previous studies } \\
\text { using batch cultures of algae have led to the assumption that lipid accumulation } \\
\text { in microalgae is a gradual process requiring at least several days for completion. } \\
\text { However, FCM reveals through changes in the chlorophyll: lipid ratio, that the } \\
\text { time span required for individual cells to change metabolic state is short. } \\
\text { Simultaneous FCM measurements of chlorophyll and nile red (neutral lipid) } \\
\text { fluorescence in individual cells of nitrogen-deficient Isochrysis populations } \\
\text { revealed a bimodal population distribution as one stage in the lipid accumulation } \\
\text { process. The fact that two discrete populations exist, with few cells in an } \\
\text { intermediate stage, suggests rapid response to a lipid trigger. Interpretations } \\
\text { of light and electron microscopic observations are consistent with this hypothesis } \\
\text { The time required for an entire population to achieve maximum } 1 \text { ipid content is } \\
\text { considerably longer than that required for a single cell, due to the variation } \\
\text { in response time among cells. In this study high lipid cultures were sometimes } \\
\text { obtained by using FCM to seperate high lipid cells from the remainder of the } \\
\text { population. FCM holds much promise for strain enhancement but considerable devel- }\end{array}$} \\
\hline \multirow{2}{*}{\multicolumn{2}{|c|}{$\begin{array}{l}\text { 17. Document Analysis opmental work, directed at providing more co } \\
\text { a. Descriptors remains to be done. } \\
\text { Algae; lipids; electron microscopy ; cell flow systems } \\
\text { b. Identifiers/Open-Ended Terms }\end{array}$}} \\
\hline & \\
\hline \multicolumn{2}{|l|}{ c. UC Categor } \\
\hline \multicolumn{2}{|l|}{$61 c$} \\
\hline \multirow{2}{*}{$\begin{array}{l}\text { 18. Availability Statement } \\
\text { National Technical Information Service } \\
\text { U.S. Department of Commerce } \\
5285 \text { Port Royal Road } \\
\text { Springfield, Virginia } 22161\end{array}$} & $\begin{array}{c}\text { 19. No. of Pages } \\
56\end{array}$ \\
\hline & $\begin{array}{r}\text { 20. Price } \\
\mathrm{A04}\end{array}$ \\
\hline
\end{tabular}

